NBER WORKING PAPER SERIES

\title{
STATE DEPENDENT EFFECTS OF MONETARY POLICY: THE REFINANCING CHANNEL
}

\author{
Martin Eichenbaum \\ Sergio Rebelo \\ Arlene Wong \\ Working Paper 25152 \\ http://www.nber.org/papers/w25152
}

\author{
NATIONAL BUREAU OF ECONOMIC RESEARCH \\ 1050 Massachusetts Avenue \\ Cambridge, MA 02138 \\ October 2018
}

We thank Adrien Auclert, Martin Beraja, David Berger, Francesco Bianci, Luigi Bocola, Christoph Boehm, Daniel Greenwald, Erik Hurst, Arvind Krishnamurthy, Moritz Lenel, Monika Piazzesi, Mikkel Plagborg-Moller, Martin Schneider, Chris Tonetti, Joe Vavra and Mark Watson for their comments, and Jose Alvarez and Laura Murphy for excellent research assistance. The views expressed herein are those of the authors and do not necessarily reflect the views of the National Bureau of Economic Research.

At least one co-author has disclosed a financial relationship of potential relevance for this research. Further information is available online at http://www.nber.org/papers/w25152.ack

NBER working papers are circulated for discussion and comment purposes. They have not been peerreviewed or been subject to the review by the NBER Board of Directors that accompanies official NBER publications.

(C) 2018 by Martin Eichenbaum, Sergio Rebelo, and Arlene Wong. All rights reserved. Short sections of text, not to exceed two paragraphs, may be quoted without explicit permission provided that full credit, including $\odot$ notice, is given to the source. 
State Dependent Effects of Monetary Policy: the Refinancing Channel

Martin Eichenbaum, Sergio Rebelo, and Arlene Wong

NBER Working Paper No. 25152

October 2018, Revised in September 2020

JEL No. E52,G31

\begin{abstract}
$\underline{\text { ABSTRACT }}$
This paper studies how the impact of monetary policy depends on the distribution of savings from refinancing mortgages. We show that the efficacy of monetary policy is state dependent, varying in a systematic way with the pool of potential savings from refinancing. We construct a quantitative dynamic life-cycle model that accounts for our findings and use it to study how the response of consumption to a change in mortgage rates depends on the distribution of savings from re financing. These effects are strongly state dependent. We also use the model to study the impact of a long period of low interest rates on the potency of monetary policy. We find that this potency is substantially reduced both during the period and for a substantial amount of time after interest rates renormalize.

Martin Eichenbaum

Department of Economics

Northwestern University

2003 Sheridan Road

Evanston, IL 60208

and NBER

eich@northwestern.edu

Sergio Rebelo

Northwestern University

Kellogg School of Management

Department of Finance

Leverone Hall

Evanston, IL 60208-2001

and CEPR

and also NBER

s-rebelo@northwestern.edu

Arlene Wong

Department of Economics

Princeton University

192A Julis Romo Rabinowitz Building

Princeton, NJ 08544

and NBER

arlenewong@princeton.edu
\end{abstract}




\section{Introduction}

In the U.S., most mortgages have a fixed interest rate and no prepayment penalties. The decision to refinance depends on the potential savings relative to the refinancing costs. In this paper, we study how the impact of monetary policy depends on the distribution of savings from refinancing the existing pool of mortgages. We show that the efficacy of monetary policy is state dependent, varying in a systematic way with the pool of savings from refinancing.

We construct a quantitative dynamic life-cycle model that highlights new trade-offs in the design of monetary policy. These results are interesting to the extent that our model is a credible representation of the data. Our model has a number quantitative properties that lend support to its credibility. First, it is consistent with the lifecycle dynamics of home-ownership rates, consumption of non-durable goods, household debt-to-income ratios and net worth. Second, it accounts for the probability that a mortgage is refinanced conditional on the potential savings from doing so. Third, and most importantly, the model accounts quantitatively for the state-dependent nature of the effects of monetary policy on refinancing decisions that we document in our empirical work.

We use our model to study how the impact of a decline in interest rates on consumption depends on the distribution of mortgage rates. One simple measure of the average savings from refinancing is the average gap between outstanding mortgages and current mortgage rates. When this gap is equal to the average value in the data, a 25 basis point drop in the mortgage rate leads to a 0.5 percent rise in consumption. In contrast, when this gap is one standard deviation above the mean, then consumption rises by 0.9 percent. So, our model implies strong state dependency in the response of consumption to a fall in mortgage rates.

We also use our model to study how the potency of monetary policy is affected by the history of interest rates. In response to the financial crisis, the Federal Reserve 
kept interest rates low for an extended period of time. The potential benefits of this policy are widely understood (see e.g. Woodford (2012) and McKay, Nakamura and Steinsson (2016)). Our model points to a potentially important cost: it reduces the potency of monetary policy during the period of low interest rates as well as during the renormalization period and its aftermath. The size of these effects is substantial. In our model-based experiments, when interest rates are below their steady-state values for six years, monetary policy is less potent for up to two years after renormalization.

Our empirical results are closely related to contemporaneous, independent work by Berger, Milbradt, Tourre, and Vavra (2018). We view their work as complementary to ours. In contrast to these authors, we use a quantitative life-cycle model to study the impact of a lengthy period of low interest rates on the efficacy of monetary policy.

We build on Wong (2020) who studies how the impact of monetary policy shocks on consumption varies by age and mortgage decisions. She finds that mortgage decisions, including refinancing, are a key determinant of why consumption responses to monetary policy shocks vary by age. Our contributions relative to Wong (2020) are two-fold. First, we document and model the state-contingent nature of refinancing decisions and its implications for the efficacy of monetary policy. Second, we focus on how the history of interest rates affects the potency of monetary policy. In pursuing these objectives, we must overcome the challenge of allowing for state-dependent effects of monetary policy in a structural model. The basic issue is that to make their decisions people must form expectations about future income, mortgage rates, house prices, and rental rates. The stochastic processes for these variables are state dependent, so our model solution technique must accommodate this dependency.

Our paper is organized as follows. Section 2 discusses the related literature. Section 3 describes the data used in our analysis. Section 4 discusses our measures of potential savings from refinancing. Our basic empirical results are contained in Section 5. We present our quantitative life-cycle model of housing, consumption and mortgage decisions in Section 6. In Section 7, we show that our model can account for the 
state-dependent effects of monetary policy that we document in our empirical work. In addition, we use the model to study the state-dependent effects of monetary policy on consumption. Section 8 uses our model to study how the potency of monetary policy is affected by an extended period of low interest rates and by a fall in refinancing costs. Section 9 provides some conclusions.

\section{Related literature}

Our paper relates to four strands of literature. The first strand is a classic literature on the effect of changes in interest rates on mortgage refinancing. Dunn and McConnell (1981) develop a theoretical model for pricing mortgage-backed securities that takes into account the effect of refinancing on the prices, risks and expected returns of such securities. In an early empirical contribution, Green and Shoven (1986) use a proportional hazard model to estimate the reduction in the probability of prepayment of fixed-rate mortgages associated with interest rate changes. Schwartz and Torous (1989) extend the Green and Shoven (1986) analysis to include the effects of seasoning, lagged refinancing rates, heterogeneity in borrowers, and seasonal effects. They use the resulting model to study the effect of prepayment on the valuation of mortgage-backed securities. Recent contributions to this literature study the distribution of mortgage rates across borrowers and emphasizes the role of transaction costs and inattention in explaining refinancing decisions. Examples include Andersen et al. (2015) and Bhutta and Keys (2016). In this paper, we extend the existing literature by studying how the distribution of mortgage rates generates state dependency in the effects of monetary policy.

The second strand of the literature is a large body of empirical work that studies consumption and refinancing responses to interest rate changes. This literature shows that households increase their expenditures when they reduce their mortgage payments and engage in cash-out refinancing (see, Beraja et al. (2018) and the references therein). 
In this paper, we extend the existing literature by showing that the effects of interest rate changes on refinancing and real outcomes depend on the distribution of mortgage rates. This type of state dependency differs from the state dependency based on loanto-valuation constraints or home equity emphasized by Beraja et al. (2018).

Because young households tend to be borrowers, while old households tend to invest in long-term bonds, monetary policy has potentially important distributional effects. So our paper is related to a third strand of the literature on the distributional effects of inflation (see Doepke and Schneider (2006) and Doepke, Schneider and Selezneva (2018) and the references therein). In contrast to these papers, we focus on the statedependent effects of monetary policy, and how these effects are shaped by past interest rate decisions made by the Federal Reserve.

The fourth strand of literature focuses on the role of the mortgage market in the transmission of monetary policy. Iacovello (2005), Garriga, Kydland and Sustek (2017) and Greenwald (2018) model the transmission mechanism using a representative borrower and saver model. In contrast, we use a heterogenous agent, life-cycle model that features transaction costs and borrowing constraints. Our model is related to work by Rios-Rull and Sanchez-Marcos (2008), Iacovelo and Pavan (2013), Auclert (2017), Berger, Guerrieri, Lorenzoni, and Vavra (2017), Garriga and Hedlund (2017), Guren, Krishnamurthy, and McQuade (2017), Guren, McKay, Nakamura, and Steinsson (2018), Kaplan, Violante and Mittman (2017), Kaplan, Violante and Moll (2018), and Wong $(2020))$.

Finally, our work is related to a recent literature that stresses the importance of mortgage refinancing as a key channel through which monetary policy affects the economy. This literature discusses why the efficacy of monetary policy depends on the state of the economy because of supply-side considerations. For example, authors like Greenwald (2018) emphasize the importance of loan-to-value ratios and debt servicingto-income ratios. Other authors focus on the effect of changes in house prices on the ability of households to refinance their mortgages. For example, Beraja, Fuster, Hurst, 
and Vavra (2018) show that regional variation in house-price declines during the Great Recession created dispersion in the ability of households to refinance.

In contrast to the previous literatures, we focus on reasons why the efficacy of monetary policy depends on the state of the economy because of demand-side considerations, i.e. households' desire to refinance their mortgages. We certainly believe that supply-side constraints were important in the aftermath of the financial crisis. But we also think that demand-side considerations were important prior to the crisis and will become increasingly important as credit markets return to normal.

\section{Data}

Our empirical work is primarily based on Core Logic Loan-Level Market Analytics, a loan-level panel data set with observations beginning in 1995. In our benchmark analysis, we end the sample in 2007. This decision is motivated by the widespread view that credit constraints were much more prevalent during the financial crisis period than in the preceding period (see e.g. Mian and Sufi (2014) and Beraja et al. (2018)).

The Core Logic data includes borrower characteristics (e.g. FICO and ZIP code) and loan-level information. ${ }^{1}$ The latter includes the principal of the loan, the mortgage rate, the loan-to-value ratio (LTV), and the purpose of the loan (whether it refinances an existing loan or finances the purchase of a new house). There is no information on the purpose of a small fraction of the loans ( 5 percent). We compute the fraction of mortgages refinanced as the ratio of mortgages that are refinanced to the total number of mortgages outstanding. This measure is conservative in the sense that some of the loans whose purpose is unknown to us could have been used to refinance existing mortgages.

For each borrower, we obtain county-level demographic information including age structure, share of employment in manufacturing, lender competitiveness, measures of

\footnotetext{
${ }^{1}$ FICO is the acronym for the credit score computed by the Fair Isaac Corporation.
} 
home-equity accumulation, educational attainment, unemployment, and per capita income. Appendix A contains a description of these variables. We also obtain county-level housing permits from the Census Building Permits Survey and county-level unemployment rates from the Current Population Survey.

We use the Freddie Mac Single Family Loan-Level dataset to study cash-out refinancing, defined as instances in which households increase the loan balance when they refinance. Cash-out refinances are identified by the Freddie Mac loan-purpose flag. These data are available since 1999.

Throughout, we confine our analysis to fixed-rate 30-year mortgages. Our results are robust to considering mortgages of different maturities. Figure 1 displays the level and first differences of the fraction of mortgages that are refinanced and the fraction of refinanced mortgages that are cash-out.

We obtain aggregate time-series variables, including forecasts of unemployment, inflation and GDP from the Survey of Professional Forecasters. We obtain time-series of the Federal Funds Rate, house price and rental rates, and income per capita from the Federal Reserve Bank of St. Louis. Finally, we obtain measures of expected inflation from the Federal Reserve Bank of Cleveland. Nominal variables are converted to real variables using the consumer price index.

\section{Measuring the potential savings from refinancing}

A key variable in our analysis is the potential savings that a household would realize by refinancing its mortgage at the current mortgage rate. Potential savings depend on a variety of factors, including old and new mortgage interest rates, outstanding mortgage balances and the precise refinancing strategy that a household pursues. In general, it is impossible to construct a simple, non-parametric summary statistic of these potential savings. Our benchmark measure is the average interest-rate gap. This measure is based on the difference between the current and alternative mortgage rate 
that household $i$ could refinance at.

We compute the average, across households, of time- $t$ interest-rate gaps between new and old loan as:

$$
A_{t}=\frac{1}{n_{t}} \sum_{i=1}^{n_{t}}\left[r_{i t}^{\text {old }}-r_{i t}^{\mathrm{new}}\right] .
$$

Here, $r_{i t}^{\text {new }}$ is the interest rate at time $t$ for a new 30-year conforming mortgage for the same FICO and region as the original mortgage. The variable $n_{t}$ denotes the number of mortgages outstanding at time $t . A_{t}$ is a real variable, since it is based on the difference between two nominal interest rates. A virtue of $A_{t}$ is that it doesn't impose any assumptions about the household's refinancing decision. The downside is that it abstracts from relevant information such as outstanding balances or the characteristics of the new mortgage (e.g. duration and fixed versus variable interest rates).

The new mortgage rate depends on borrower characteristics, including FICO and region. We group FICO scores into the following bins: below 600, 600-620, 620-640,... ,...,760-780, and greater than 780. We condition on the household's region to take into account the possibility that mortgage rates vary by region, say because of differences in income or house price growth. ${ }^{2}$ We also considered versions of $r_{i t}^{\text {new }}$ that condition in a non-parametric way on additional variables such as the loan-to-valuation ratio or the mortgage balance. Adding these measures does not significantly improve the ability of $r_{i t}^{\text {new }}$ to fit the distribution of interest rates across new borrowers.

The annualized unconditional quarterly mean and standard deviation of $A_{t}$ is -14 basis points and 70 basis points, respectively. The distribution of the interest rate gap varies considerably over time. To make this point concrete, Figure 2 displays the distribution of interest-rate gaps in 1997.Q4 and 2000.Q4. These dates correspond to local turning points in the average real mortgage rate. The fraction of households with positive savings and the average savings is much higher in 1997.Q4 than in 2000.Q4.

\footnotetext{
${ }^{2}$ As a practical matter, we find that our results are robust to not conditioning on the household's region. This finding is consistent with Hurst, Keys, Seru and Vavra (2016) who find little evidence of spatial variation in mortgage rates.
} 
In Appendix C3, we consider three alternative measures of the savings from refinancing. The first is the fraction of mortgages with a positive interest-rate gap. The second is based on the average present value of savings from pursuing a simple refinancing strategy. The third is based on the fraction of loans above a time-varying threshold for refinancing, defined in Agawal, Driscoll and Laibson (2013). Our results are robust to using these alternative measures.

The average cross-sectional dispersion in the average rate gap is 1 percent. In Appendix B, we report the correlation between the average rate gap and observable characteristics (unemployment rate, per capita income, share of college educated, home equity accumulation, median age, manufacturing share, and share of males in the population). Other things equal, the average rate gap is higher in areas with a higher unemployment rate and it is a decreasing function of per capita income, the share of the population that is college educated and the amount of home equity accumulation.

\section{Empirical results}

In this section, we study how the impact on refinancing activity of a change in the mortgage rate depends on the average savings from refinancing. We report basic correlations based on ordinary least squares (OLS) in Appendix D. Here, we implement an instrumental-variable (IV) strategy for measuring the marginal effect of a drop in mortgage rates on the fraction of loans that are refinanced. Our main results are that this marginal effect is state dependent as is the impact of a fall in interest rates on economic activity.

\subsection{State dependency and refinancing activity}

We begin by considering the regression:

$$
\rho_{t+4}^{c}=\beta_{0} X^{c}+\beta_{1} \Delta R_{t}^{M}+\beta_{2} \Delta R_{t}^{M} \times A_{t-1}^{c}+\beta_{3} A_{t-1}^{c}+\beta_{4} Z_{t-1}+\beta_{5} Z_{t-1}^{c}+\eta_{t}^{c} .
$$


Here, $\rho_{t+4}^{c}$ is the fraction of mortgages refinanced in county $c$ between quarters $t$ and $t+4, X^{c}$ is a vector of county fixed effects, and $\Delta R_{t}^{M}$ denotes the percentage fall in our measure of the mortgage rate. ${ }^{3}$ The variable $A_{t-1}^{c}$ is the average interest-rate gap for mortgages in county $c$ at time $t-1$. The vector $Z_{t-1}$ denotes a set of timevarying controls. Motivated by results in Nakamura and Steinsson (2018) we include as controls the average forecast of the Survey of Professional Forecasters (SPF) for the following variables: real GDP growth (two year ahead), the civilian unemployment rate (two years ahead), and the CPI inflation rate (one and two years ahead). The variable $Z_{t-1}^{c}$ includes the following county-level controls: the unemployment rate, average logchange in real home equity, one-year lag of the refinancing rate, median age, share of employment in manufacturing, share of college educated and a Herfindahl index of the mortgage sector. ${ }^{4}$ We include the latter index, developed in Scharfstein and Sunderam (2013), to capture any variation in pass through by region, induced by time variation in competition across counties. We cluster the standard errors at the county level.

The coefficient $\beta_{1}$ measures the effect of a change in mortgage rates on refinancing rates when $A_{t-1}^{c}$ is zero. The coefficient $\beta_{2}$ measures how the effect of an interest rate change depends on the level of $A_{t-1}^{c}$. Identification of $\beta_{1}$ and $\beta_{2}$ comes from both cross-sectional and time-series variation in the response of refinancing to interest rate changes. $^{5}$

We estimate regression (2) using two instruments for $\Delta R_{t}^{M}$ that exploit exogenous changes in monetary policy. ${ }^{6}$ The instruments are based on high-frequency movements

\footnotetext{
${ }^{3}$ If the mortgage rate falls by 25 basis points, $\Delta R_{t}=0.25$. Defining $\Delta R_{t}$ as the fall in the interest rate, instead of the interest rate change makes the regression coefficients easier to interpret.

${ }^{4}$ Our results are robust to including as additional controls the fraction of mortages in county $c$ that have adjustable rates and the interaction of this variable with the monetary policy shock.

${ }^{5}$ In practice, most of the variation in refinancing rates comes from time-series variation in interest rates. One way to see this result is to regress the rate of refinancing in county $c$ at time $t$ on time and county fixed effects. County fixed effects account for less than 20 percent of the variation in refinancing rates.

${ }^{6}$ It is difficult to give a causal interpretation to the OLS-based estimates of $\beta_{1}$ and $\beta_{2}$ because of potential endogeneity bias caused by any omitted variable that affects both mortgage rates and savings from refinancing. For example, suppose that during a recession more people are unemployed
} 
in the Federal Funds futures rate and the two-year Treasury bond yield in a small window of time around Federal Open Market Committee (FOMC) announcements. ${ }^{7}$

In the case of the Federal Funds futures, the monetary policy shock is defined as:

$$
\varepsilon_{t}=\frac{D}{D-t}\left(y_{t+\Delta^{+}}-y_{t-\Delta^{-}}\right) .
$$

Here, $t$ is the time when the FOMC issues an announcement, $y_{t+\Delta^{+}}$is the Federal Funds futures rate shortly after $t, y_{t-\Delta^{-}}$is the Federal Funds futures rate just before $t$, and $D$ is the number of days in the month. The term $D /(D-t)$ adjusts for the fact that Federal Funds futures contracts settle on the average effective overnight Federal Funds rate. We consider a 60 -minute window around the announcement that starts $\triangle^{-}=15$ minutes before the announcement. This narrow window makes it highly likely that the only relevant shock during that time period (if any) is the monetary policy shock. Following Cochrane and Piazessi (2002) and others, we aggregate the identified shock to construct a quarterly measure of the monetary policy shock. This aggregation relies on the assumption that shocks are orthogonal to economic variables in that quarter. The standard deviation of the implied monetary policy shock is 12 basis points.

In Appendix C2, we report our empirical analysis when we measure a monetary policy shock using the 2-year Treasury yield:

$$
\varepsilon_{t}=y_{t+\Delta^{+}}-y_{t-\Delta^{-}} .
$$

Instrumental variable results. We begin by providing evidence that monetarypolicy shocks are a strong instrument for changes in mortgage rates. First, we show that monetary policy shocks significantly affect mortgage rates. To this end, we estimate via

and therefore less willing to incur the fixed costs associated with refinancing. Also, suppose that the recession occurred because the Fed raised interest rates. Then, $\Delta R_{t}^{M}$ and $\Delta R_{t}^{M} \times A_{t-1}^{c}$ would be positively correlated with $\eta_{t}^{c}$ creating a downward bias in $\beta_{1}$ and $\beta_{2}$.

${ }^{7}$ This approach has been used by Kuttner (2001), Gürkaynak, Sack and Swanson (2005), Cochrane and Piazessi (2002), Nakamura and Steinsson (2018), Gorodnichenko and Weber (2015), and Wong (2020), among others. 
OLS the contemporaneous change in the 30-year mortgage rate after a one percentage point monetary policy shock. Our point estimate is 60 basis points with a standard error of 28 basis points. Taking sampling uncertainty into account, this estimate is consistent with those of Gertler and Karadi (2015, Table 1), which range from 17 to 48 basis points, depending on the set of instruments used to identify the monetary shock.

Second, we estimate the following first-stage regressions:

$$
\begin{aligned}
\Delta R_{t}^{M} & =\alpha_{0}+\alpha_{1} \varepsilon_{t}+\alpha_{2} \varepsilon_{t} \times A_{t-1}^{c}+\eta_{1 t} \\
\Delta R_{t}^{M} A_{t-1}^{c} & =\gamma_{0}+\gamma_{1} \varepsilon_{t}+\gamma_{2} \varepsilon_{t} \times A_{t-1}^{c}+\eta_{2 t} .
\end{aligned}
$$

Table 1 reports our first-stage regression estimates. The $F$ test for the joint significance of the regression coefficients is greater than ten. This result is consistent with the view that policy shocks are strong instruments. We also perform the Stock-Yogo (2005) test for the null hypothesis of weak instruments. The test statistic is 79.5, which firmly rejects the null of weak instruments.

Panel A of Table 2 reports results based on estimating regression (2). We cluster the standard errors at the county level. The estimated values of $\beta_{1}$ and $\beta_{2}$ are statistically significant at the one percent significance level. Estimated parameters on controls are reported in Appendix C3. That appendix also documents the robustness of the estimated value of $\beta_{1}$ to including various lagged values of the refinancing rate in our empirical specification. Appendix D contains the analogue of Panel A of Table 2 generated using OLS.

To interpret the coefficients in Panel A of Table 2, suppose that all independent variables in regression (2) are initially equal to their time-series averages and that the average interest-gap is initially equal to its mean value of -14 basis points. The unconditional average share of loans that is refinanced is 7.9 percent. The estimates in Panel A of Table 2 imply that a 25 basis point drop in mortgage rates raises the share of loans that is refinanced to 8.0 percent. ${ }^{8}$ Now, suppose that the drop in mortgage rates

\footnotetext{
${ }^{8}$ This value is given by $7.9 \%+0.25 \times\left(\beta_{1}+\beta_{2} \times-0.14\right)=8.0 \%$.
} 
occurs when the average interest-rate gap is equal to 56 basis points. The latter is the mean value of -14 basis points plus one standard deviation (70 basis points). Then, a 25 basis points drop in mortgage rates raises the share of loans that is refinanced to 12.6 percent. ${ }^{9}$ So, the marginal impact of a one standard-deviation increase in the average interest-rate gap is 4.7 percent. This effect is large relative to the average annual refinancing rate, 7.9 percent.

Figure 3 reports the impulse response function of the fraction of mortgages refinanced to a 50 basis point drop in the mortgage rate. We compute this function for two cases corresponding to whether the average interest-gap is initially equal to -14 basis points or to 56 basis points. Panel A shows that in the first case there is a weak response of refinancing to the interest rate cut. Panel B shows that in the second case there is a persistent rise in refinancing activity over a two-year period.

A natural question is whether there is substantial variation over time in the impact of mortgage rate reductions on refinancing rates. To answer this question we use the estimated version of regression (2) to calculate the effect of a 50 basis points reduction in the mortgage rate on the refinancing rate at each point in time in our sample. The solid line in Figure 4 plots this effect and the dashed lines correspond to the 95 percent confidence interval (computed using the delta method). There is substantial variation in the potency of monetary policy through the refinancing channel. This effect was most potent in 1998 and 2003 and least potent in 1995 and 1999. These dates correspond to periods in which the average rate gap is high and low, respectively. We discuss our model's implication for these effects in Section 5.

As a robustness test, we also included in regression (2) interaction terms of the form $\Delta R_{t}^{m} Z_{t-1}^{c}$. These results are reported in Appendix C3. The implied estimates of $\beta_{2}$ are statistically indistinguishable from those reported in Panel A of Table 2. The fact that including the interaction terms does not change the estimated elasticities implies that the state dependency that we highlight is distinct from other potential mechanisms

\footnotetext{
${ }^{9}$ This value is given by $7.9 \%+0.25 \times\left(\beta_{1}+\beta_{2} \times 0.56\right)=12.6 \%$.
} 
explored in the literature. These mechanisms include, for instance, differential responses in refinancing to a decline in mortgage rates due to differences in competitiveness of the local lending market. It is also distinct from state dependency related to cross-county variation in the value of home equity.

\subsection{Cash-out refinancing}

In this subsection, we use the Freddie Mac data on single-family loans to study how cash-out refinancing responds to changes in mortgage rates. Cash-out refinancing occurs when the balance of the new mortgage is higher than that of the old mortgage. Mian and Sufi (2014) show that households predominantly use this type of refinancing to increase their consumption. So, cash-out refinancing plays an important role in the determining the effects of changes in interest rates on consumption.

We run a version of regression (2) in which the dependent variable is the fraction of total loans with cash-out refinancing in county $c$ between quarters $t$ and $t+4$. Panel B of Table 2 reports our results. Both $\beta_{1}$ and $\beta_{2}$ are significant at the one-percent significance level. To interpret these coefficients, suppose that all independent variables in regression (2) are initially equal to their time-series averages and that the average interest-gap is initially equal to its mean value of -14 basis points. The estimates in Panel B of Table 2 imply that a 25 basis point drop in mortgage rates raises the share of loans with cash-out refinancing by 1.2 percent. Now suppose that the drop in mortgage rates occurs when the average interest-rate gap is 56 basis points. Then, a 25 basis point drop in mortgage rates raises the share of loans with cash-out refinancing by 4.3 percent. So, the marginal impact of a one standard deviation increase in the average interest-rate gap is 3.1 percent. This effect is large relative to the average annual cash-out refinancing rate, 5.5 percent.

We also estimate a version of regression (2) in which the dependent variable is the log change in the balance of mortgages with cash-out refinancing. Panel $\mathrm{C}$ of Table 2 reports our results. To interpret these coefficients, suppose that all independent 
variables in regression (2) are initially equal to their time-series averages and that the average interest-gap is initially equal to its mean value of -14 basis points. The estimates in panel $\mathrm{C}$ of Table 2 imply that a 25 basis points drop in mortgage rates raises the balance of the mortgages with cash-out refinancing by 5.2 percent. Now suppose that the drop in mortgage rates occurs when the average interest-rate gap is 56 basis points. Then, a 25 basis point drop in mortgage rates raises the balance of the mortgages with cash-out refinancing by 8.9 percent. So, the marginal impact of a one standard deviation increase in the average interest-rate gap is 3.8 percent. The median mortgage balance in 2007 was roughly $\$ 123,000$. It follows that a 3.8 percent increase in mortgage balance translates into equity extraction of roughly $\$ 4,700$, a substantial amount of cash that becomes available for consumption.

\subsection{Refinancing and economic activity}

We now study how a change in mortgage rates affects economic activity. To be clear, we are not the first to establish that changes in mortgage rates induced by monetary policy shocks affect economic activity. We are simply establishing that these effects are state dependent.

Our first measure of economy activity is the county-level unemployment rate. Our second measure is the number of county-level permits required for new, privately-owned residential buildings. This series, produced by the Census Building Permits Survey since 2000, is of particular interest to us because it is the only component of the Conference Board's leading indicator index available at the county level. We aggregate these monthly data to a quarterly frequency.

We begin by considering a regression where the dependent variable is the change in the unemployment rate between quarter $t$ and $t+4$ :

$$
\Delta \text { Unemployment }_{t, t+4}=\theta_{0} X^{c}+\theta_{1} \Delta R_{t}^{M}+\theta_{2} \Delta R_{t}^{M} \times A_{t-1}^{c}+\theta_{3} A_{t-1}^{c}+\eta_{t}^{c}
$$

Table 3 reports our IV estimates obtained using the instruments discussed in Section 
4.1. Standard errors are clustered at the county level. The point estimate of $\theta_{1}$ is statistically significant at a 10 percent level while $\theta_{2}$ is statistically significant at the 1 percent level. To interpret the point estimates, suppose that all independent variables in regression (5) are initially equal to their time-series averages. Our estimates imply that a 25 basis point drop in mortgage rates lowers the unemployment rate by 0.6 percent. Suppose that the drop in mortgage rates occurs when the average interest-rate gap is equal to 56 basis points. Then a 25 basis point drop in mortgage rates lowers the unemployment rate by 1.8 percent. So, the marginal impact of a one standard deviation increase in the average interest-rate gap is 1.2 percent.

We now consider a version of the regression where the dependent variable is the year-on-year quarterly log-change in new building permits:

$$
\Delta \log \text { Permits }_{t, t+4}=\theta_{0} X^{c}+\theta_{1} \Delta R_{t}^{M}+\theta_{2} \Delta R_{t}^{M} \times A_{t-1}^{c}+\theta_{3} A_{t-1}^{c}+\eta_{t}^{c} .
$$

Table 3 reports our IV estimates. Both $\theta_{1}$ and $\theta_{2}$ are statistically significant at a 1 percent significance level. To interpret the point estimates suppose that all independent variables in regression (5) are initially equal to their time-series averages. The estimates in column 2 imply that a 25 basis point drop in mortgage rates raises the percentage change in new permits to 17.0. Now suppose that the drop in mortgage rates occurs when the average interest-rate gap is equal to 56 basis points. Then a 25 basis points drop in mortgage rates raises the percentage change in new permits to 23.6 percent. So, the marginal impact of a one standard deviation increase in the average interest-rate gap is 6.6 percent. This effect is large relative to a one standard deviation change in housing permits (26 percent).

Overall, we view the results of this section as providing strong support for two hypotheses. First, the effect of a change in the interest rate on refinancing activity is state dependent. When measures of the average gains from refinancing are high, a given fall in the interest rate induces a larger rise in refinancing activity. Second, the effect of a change in the interest rate on economic activity, as measured by new housing 
permits or the rate of unemployment, is state dependent in a similar way. This finding is consistent with the results in Di Maggio, Kermani, Keys, Piskorski, Ramcharan, Seru, and Yao (2017). These authors show that households who experience a drop in monthly mortgage payments increase their car purchases. It is also consistent with results in Berger, Milibrandt, Tourre and Vavra (2018) who show that there is a state-dependent rise in auto registrations when interest rates fall.

\section{A life-cycle model}

To analyze the state-dependent effects of monetary policy, we use a life-cycle model with incomplete markets, short-term borrowing constraints, refinancing costs, and loanto-value constraints on mortgages. Our model generalizes the framework in Wong (2020) to allow for state dependency in the aggregate state process for the interest rate, income, house prices and rental rates. This generalization allows us to incorporate state-dependent feedback effects of monetary policy shocks on aggregate variables.

We use the model for three purposes. First, we quantify the structural factors that drive the state-dependent effects of monetary policy. Second, we estimate the statedependent effect of an exogenous change in the interest rate on consumption. Third, we study how the potency of monetary policy is affected by a long period of low interest rates.

It is evident that there is a great deal of heterogeneity across households in their propensity to refinance in response to an interest rate cut. One way to capture that heterogeneity is to allow for a great deal of heterogeneity in unobserved fixed costs of refinancing. An alternative is to model that heterogeneity in refinancing behavior as reflecting demographics, initial asset holdings and idiosyncratic income shocks. We choose the second strategy to minimize the role of unobservable heterogeneity. An advantage of this approach is that it is consistent with the positive correlation between consumption growth and refinancing decisions at the household level. This correlation is 
important for generating a response of aggregate consumption to interest rate changes. ${ }^{10}$

Households. The economy is populated by a continuum of people indexed by $j$. We think of the first period of life as corresponding to 25 years of age. Each person can live up to 60 years. The probability of dying at age $a$ is given by $1-\pi_{a}$. Conditional on surviving, people work for 40 years and retire for 20 years. The upper bound on a person's life is 85 years $(T=85)$.

The momentary utility of person $j$ who is a periods old at time $t$ is given by:

$$
u_{j a t}=\frac{\left(c_{j a t}^{\alpha} h_{j a t}^{1-\alpha}\right)^{1-\sigma}-1}{1-\sigma}, \sigma>0 .
$$

Here, $c_{j a t}$ and $h_{j a t}$ denote the consumption and housing services of person $j$ who is $a$ periods old at time $t$. People derive housing services from either renting or owning a house. Renters can freely adjust the stock of rental housing in each period. To buy a home of size $h$, households pay a transaction cost $\Phi^{\text {new }} h$. To refinance an existing mortgage, homeowners pay a lump-sum transaction cost $\Phi^{\text {refi }} \cdot{ }^{11}$ The stock of housing depreciates at rate $\delta$.

Upon death, the wealth of person $j$ who is a periods old at time $t, W_{j a t}$, is passed on as a bequest. If a person has an outstanding mortgage upon death, the house is sold to pay the mortgage and the remainder of the estate is passed on as a bequest. Person $j$ derives utility $B\left(W_{j a t}^{1-\sigma}-1\right) /(1-\sigma)$ from this bequest. Here $B$ is a positive scalar. The presence of a bequest motive allows the model to be consistent with the fact that many people die with large amounts of assets (see e.g. Huggett (1996) and De Nardi and Yang (2014)). More importantly, this motive helps the model generate the fall in consumption and house downsizing that we observe in data for older consumers. The

\footnotetext{
${ }^{10}$ Recent work that emphasizes the correlation between household consumption and interest rate changes for understanding the behavior of aggregate consumption includes Auclert (2017), Kaplan, Violante and Moll (2018), and Wong (2020).

${ }^{11}$ See DeFusco and Mondragon (2018) for evidence that fixed costs, including closing costs and refinancing fees, are important determinants of refinancing decisions.
} 
reason is that, as people get older, the bequests receive a higher weight in the utility function relative to consumption and housing.

Income processes. The time- $t$ labor income of person $j$ who is $a$ periods old at time $t, y_{j a t}$, is given by:

$$
\log \left(y_{j a t}\right)=\chi_{a}+\eta_{j t}+\phi_{a} \log \left(Y_{t}\right)
$$

Here, $\chi_{a}$ and $\eta_{j t}$ are a deterministic age-dependent component and a stochastic, idiosyncratic component of $y_{j a t}$, respectively. We assume that

$$
\eta_{j t}=\rho_{\eta} \eta_{j t-1}+\varepsilon_{\eta t}
$$

where $\left|\rho_{\eta}\right|<1$ and $\varepsilon_{\eta t}$ is a white noise process with standard deviation, $\sigma_{\eta}$. The variable $Y_{t}$ denotes aggregate real income. The term $\phi_{a}$ captures the age-specific sensitivity of $y_{\text {jat }}$ to changes in aggregate real income.

As in Guvenen and Smith (2014), we assume that a person receives retirement income that consists of a government transfer. The magnitude of this transfer is a function of the labor income earned in the year before retirement.

Mortgages. Home purchases are financed with fixed-rate mortgages. An individual $j$ who enters a mortgage loan at age $a$ in date $\tau$, pays a fixed interest rate $R_{j a \tau}$ and makes a constant payment $M_{j a \tau}$. The mortgage principal evolves according to:

$$
b_{j, a+1, t+1}=b_{j a t}\left(1+R_{j a \tau}\right)-M_{j a \tau} .
$$

Mortgages are amortized over the remaining life of the individual. So, the maturity of a new loan for an $a$-year old person is $m(a)=T-a$. The fixed interest rate $R_{j a \tau}$ is equal to $r_{\tau}^{m(a)}$, which is the time- $\tau$ market interest rate for a mortgage with maturity $m(a)$.

The mortgage payment, $M_{j a \tau}$, is given by:

$$
M_{j a \tau}=\frac{b_{j a \tau}}{\sum_{k=1}^{m(a)}\left(1+R_{j a \tau}\right)^{-k}} .
$$


If a person refinances or buys a new house at time $t$, the new mortgage rate is given by the current fixed mortgage rate: ${ }^{12}$

$$
R_{\text {jat }}=r_{\tau}^{m(a)}
$$

Bond holdings. A person can invest in a one-year bond that yields an interest rate $r_{t}$. The variable $s_{j a t}$ denotes the time- $t$ bond holdings of person $j$ who is $a$ years old at time $t$. Bond holdings have to be non-negative, $s_{j a t} \geq 0$.

Loan-to-value constraint. At the time of origination, the size of a mortgage loan must satisfy the constraint:

$$
b_{j a t} \leq(1-\phi) p_{t} h_{j a t} .
$$

Here, $p_{t}$ is the time- $t$ price of a unit of housing and $\phi p_{t} h_{j a t}$ is the minimum down payment on a house.

State variables. The state variables in our model are $z=\{a, \eta, K, S\}$. Here, $a, \eta$, and $K$ denote age, idiosyncratic labor income, and asset holdings, respectively. The vector $K$ includes short-term asset holdings $(s)$, the housing stock ( $h^{\text {own }}$ for homeowners, zero for renters), the mortgage balance ( $b$ for homeowners, zero for renters), and the interest rate $(R)$ on an existing mortgage. Finally, $S$ denotes the aggregate state of the economy which consists of the logarithm of real output, $y$, the logarithm of real housing prices, $p$, the real interest rate on short-term assets, $r$, and the logarithm of economy-wide average positive savings from refinancing, $A$. We assume that $S$ is a stationary stochastic process (see Section 6.2).

Mortgage interest rate and rental rates. It is difficult for traditional asset pricing models to account for the empirical properties of mortgage interest rates, rental rates

\footnotetext{
${ }^{12}$ In practice, U.S. mortgage rates can depend on the size of the loan. For example, jumbo mortgages (loans sizes that exceed the maximum guaranteed by Fannie Mae and Freddie Mac) have higher interest rates than non-jumbo mortgages. To simplify, we abstract from this feature in our analysis.
} 
and housing prices (see Piazzesi and Schneider (2016)). For this reason, we assume that these variables depend on the aggregate state of the economy via functions that we estimate. This approach allows the model to be consistent with the empirical properties of these variables.

The mortgage interest rate, $r_{t}^{m}$, is given by

$$
r_{t}^{m}=a_{0}^{m}+a_{1}^{m} r_{t}+a_{2}^{m} y_{t}
$$

This formulation captures, in a reduced-form way, both the term premia and changes in risk premia that arise from shocks to the aggregate state of the economy. ${ }^{13}$

The real rental rate is given by:

$$
\log \left(p_{t}^{r}\right)=\alpha_{0}+\alpha_{1} r_{t}+\alpha_{2} y_{t}+\alpha_{3} p_{t}
$$

Value functions. We write people's maximization problems in recursive form. To simplify notation, we suppress the dependence of variables on $j, a$ and $t$. Denote by

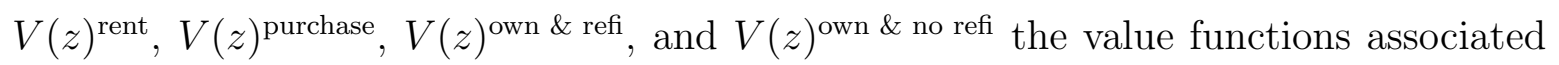
with renting, purchasing, owning a home and refinancing, and owning a home and not refinancing, respectively. A person's overall value function, $V(z)$, is the maximum of these value functions:

$$
V(z)=\max \left\{V(z)^{\text {rent }}, V(z)^{\text {purchase }}, V(z)^{\text {own \& refi }}, V(z)^{\text {own \& no refi }}\right\}
$$

A renter maximizes

$$
V(z)^{\mathrm{rent}}=\max _{c, h^{\mathrm{rent}}, s^{\prime}} u\left(c, h^{\mathrm{rent}}\right)+\beta E\left[\pi_{a} V\left(z^{\prime}\right)+\left(1-\pi_{a}\right) B \frac{\left(W^{\prime}\right)^{1-\sigma}-1}{1-\sigma}\right],
$$

subject to the budget constraint,

$$
c+s^{\prime}+p^{r} h^{\text {rent }}=y+(1-\delta) p h^{\text {own }}+(1+r) s-b(1+R),
$$

\footnotetext{
${ }^{13}$ In practice, mortgage rate can vary with loan size. For computational reasons, we abstract from this issue in our analysis.
} 
and the borrowing constraint on short-term assets,

$$
s^{\prime} \geq 0
$$

The discount rate and the probability of survival are denoted by $\beta$ and $\pi_{a}$, respectively. The term $B\left[\left(W^{\prime}\right)^{1-\sigma}-1\right] /(1-\sigma)$ represents the utility from bequests. The terms $(1-\delta) p h^{\text {own }}$ and $b(1+R)$ in equation (12) take into account the possibility that the renter used to be a home owner. The renter's housing stock and mortgage debt are both zero:

$$
h^{\text {own }}=b^{\prime}=0 \text {. }
$$

A household who decides to purchase a new home maximizes:

$$
V(z)^{\text {purchase }}=\max _{c, s^{\prime}, h^{\prime} \text { own }, b^{\prime}} u\left(c, h^{\text {own }}\right)+\beta E\left[\pi_{a} V\left(z^{\prime}\right)+\left(1-\pi_{a}\right) B \frac{\left(W^{\prime}\right)^{1-\sigma}-1}{1-\sigma}\right],
$$

subject to the budget constraint

$$
c+s^{\prime}+p h^{\text {own }}-b^{\prime}=y+(1-\delta) p h^{\text {own }}+(1+r) s-b(1+R)-\Phi^{\text {new }} h^{\text {own }},
$$

the borrowing constraint on short term assets,

$$
s^{\prime} \geq 0
$$

and the minimal down payment required on the mortgage,

$$
b^{\prime} \leq(1-\phi) p h^{\text {own }} .
$$

The new mortgage interest rate is given by:

$$
R^{\prime}=r^{m}
$$

A homeowner who does not refinance his mortgage maximizes:

$$
V(z)^{\text {own } \& \text { no refi }}=\max _{c, s^{\prime}} u\left(c, h^{\text {own }}(1-\delta)\right)+\beta E\left[\pi_{a} V\left(z^{\prime}\right)+\left(1-\pi_{a}\right) B \frac{\left(W^{\prime}\right)^{1-\sigma}-1}{1-\sigma}\right] \text {, }
$$


subject to the budget constraint,

$$
c+s^{\prime}=y+(1+r) s-M,
$$

the law of motion for the mortgage principal

$$
b^{\prime}=b(1+R)-M,
$$

and the short-term borrowing constraint

$$
s^{\prime} \geq 0
$$

Since the person doesn't refinance, the interest rate on his mortgage remains constant

$$
R^{\prime}=R
$$

The mortgage payment is given by equation (7).

A homeowner who refinances, maximizes:

$$
V(z)^{\text {own \& refi }}=\max _{c, s^{\prime}, h^{\prime \text { own }}, b^{\prime}} u\left(c, h^{\text {own }}\right)+\beta E\left[\pi_{a} V\left(z^{\prime}\right)+\left(1-\pi_{a}\right) B \frac{\left(W^{\prime}\right)^{1-\sigma}-1}{1-\sigma}\right],
$$

subject to the budget constraint

$$
c+s^{\prime}+p h^{\text {own }}-b^{\prime}+\Phi^{\text {refi }}=y+(1-\delta) p h^{\text {own }}+(1+r) s-b(1+R),
$$

the borrowing constraint on short-term assets,

$$
s^{\prime} \geq 0
$$

and the minimal down payment required on the mortgage,

$$
b^{\prime} \leq(1-\phi) p h^{\text {own }}
$$

The new mortgage interest rate is given by:

$$
R^{\prime}=r^{m}
$$

The problem for a retired person is identical to that of a non-retired person, except that social security benefits replace labor earnings. 


\subsection{Calibration}

Our parameter values are summarized in Table 4 . We set $\sigma=2$ and choose $B, \beta$, and $\alpha$ to target key moments of the savings and asset-holding profiles. These moments include the average home ownership rate, the liquid wealth-to-income ratio for workingage households, and the share of wealth held by older households (aged 65+) from the 2007 Survey of Consumer Finances. The idiosyncratic-income parameters $\rho_{\eta}$ and $\sigma_{\eta}$ are chosen to match the annual persistence and standard deviation of residual earnings in the Panel Study of Income Dynamics. The deterministic, age-specific vector $\chi_{a}$ is chosen to match average log earnings by age estimated by Guvenen et al. (2015). We choose $\phi_{a}$ to match the correlation between real aggregate income per capita and agespecific earnings in the Current Population Survey. The house depreciation rate, $\delta$, is chosen to be consistent with the average ratio of residential investment to the residential stock from the Bureau of Economic Analysis. We set $\phi$ so that, in line with Landvoigt, Piazzesi and Schneider (2015), the minimum mortgage downpayment is 20 percent. We estimate the parameters of the processes for mortgage rates $\left(a_{0}^{m}, a_{1}^{m}\right.$, and $a_{2}^{m}$ in equation (8)) and and rental rates $\left(\alpha_{0}, \alpha_{1}, \alpha_{2}\right.$, and $\alpha_{3}$ in equation (9)). We discuss the empirical fit of these processes in Section 6.2.

Recall that we think of the first period of life as 25 years of age. Age-dependent survival probabilities are given by the U.S. actuarial life-expectancy tables and assume a maximum age of 85. Assets and income in the first period are calibrated to match average assets and income for persons of ages 20 to 29 in the 2004 Survey of Consumer Finances. Mortgage rates are calibrated using the mortgage rate in the beginning of the sample.

We set the fixed cost of refinancing, $\Phi^{\text {refi }}$, equal to $\$ 2,100$ (2 percent of median house price) to match the average quarterly fraction of new loans ( 4.5 percent). This value is consistent with the range of costs provided in the Federal Reserve's "Consumer 
Guide to Mortgage Refinancings" and with the evidence in LaCour-Little (2000). ${ }^{14}$ The fixed costs of refinancing include the appraisal fee, the inspection fee, and the attorney review fee. We set the transaction cost of buying a new home, $\Phi^{\text {new }}$, equal to 5 percent of the house price. This value is consistent with empirical evidence as well as the values used in the literature. ${ }^{15}$

\subsection{The evolution of the aggregate states}

To solve their decision problem, people must form expectations about their future income, mortgage rates, house prices, and rental rates. Because of its partial equilibrium nature, our model does not imply a reduced-form representation for these variables. It seems natural to assume that people base their expectations on a time-series model that has good forecasting properties.

Recall that we model the mortgage rate with maturity $m$ as a function of $r_{t}$ and $y_{t}$ (see equation (8)). We estimate this function using OLS. Table 5 reports our estimates. Figure 5 shows that the estimated version of equation (8) does a very good job at accounting for the time-series behavior of the 30-year mortgage rate over the period 1989-2008.

It is hard for traditional asset-pricing models to account for the empirical relation between rental rates and housing prices (see, e.g., Piazzesi and Schneider (2016)). So, we model the real rental rate as a linear function of $r_{t}, y_{t}$ and $p_{t}$ (see equation (9)). We estimate this function using the national house price and rent indices obtained from the Federal Reserve Bank Dallas. Figure 6 shows that the estimated version of equation (9) does a very good job at accounting for the time-series behavior of the logarithm of the house price-to-rent ratio over the period 1989-2008.

We estimate a suite of quarterly time-series models for the aggregate-state vector

\footnotetext{
${ }^{14}$ https://www.federalreserve.gov/pubs/refinancings

${ }^{15}$ See Diaz and Luengo-Prado (2012), Berger et al. (2018), and Zillow's home guide (2018) at https://www.zillow.com/sellers-guide/closing-costs-for-sellers.
} 
$S_{t}=\left\{\log \left(r_{t}\right), \log \left(y_{t}\right), \log \left(p_{t}\right), \log \left(A_{t}\right)\right\}$. We eliminate from consideration models with explosive dynamics and judged the remaining models balancing parsimony and the implied average (over time and across variables) root-mean-square-error (RMSE) of one-year-ahead forecasts. Parsimony is important for the computational tractability of our structural model.

We settled on the following model for quarterly changes in $S_{t}$ :

$$
\Delta S_{t}=B_{0}+B_{1} \Delta S_{t-1}+B_{2} \Delta \log \left(r_{t-1}\right) a_{t-1}+u_{t} .
$$

Here, $B_{1}$ is a $4 \times 4$ matrix, $B_{0}$ and $B_{2}$ are $4 \times 1$ vectors, and $u_{t}$ is a $4 \times 1$ Gaussian disturbance. The variable $a_{t-1}$ is the logarithm of economy-wide average positive savings from refinancing at time $t-1, \log \left(A_{t-1}\right)$.

Appendix E reports the average RMSE for the alternative models that we considered. These models include specifications with up to two lags of $\Delta S_{t}$ and $\Delta \log \left(r_{t-1}\right) a_{t-1}$. In addition, we included cross products of all the variables in different combinations as well as squares and cubes of the different variables. We also considered different moments of various measures of the gains from refinancing. For example, we replaced $a_{t}$ with average savings (in levels), median savings, average interest-rate gap, logarithm of average positive interest-rate gap, median of the interest-rate gap, fraction of mortgages with positive savings, and standard deviation of savings. To conserve on space we do not report these results.

None of the RMSEs associated with the alternative specifications was smaller, taking sampling uncertainty into account, than the RMSE associated with specification (14). Specification (14) did have a statistically significant smaller RMSE than many of the alternatives.

Table 6 reports point estimates and standard errors for $B_{1}$ and $B_{2}$ associated with specification (14). The coefficients in $B_{2}$ are statistically significant at the one percent level for $\log \left(r_{t}\right)$ and $\log \left(p_{t}\right)$ and at the 5 percent level for $a_{t}$.

A natural question is whether the inclusion of $a_{t}$ and $\Delta r_{t-1} a_{t-1}$ in specification 
(14) helps reduce the RMSE for the three aggregate variables. $\log \left(r_{t}\right), \log \left(y_{t}\right)$, and $\log \left(p_{t}\right)$. Simply adding $a_{t}$ to a linear VAR for $\log \left(r_{t}\right), \log \left(y_{t}\right)$, and $\log \left(p_{t}\right)$, reduces the average RMSE for $\log \left(r_{t}\right), \log \left(y_{t}\right)$, and $\log \left(p_{t}\right)$ in a modest but statistically significant way (from 0.0298 to 0.0258). Adding the interaction term $\Delta r_{t-1} a_{t-1}$ results in an even more modest, but statistically significant reduction, in the average RMSE for $\log \left(r_{t}\right)$, $\log \left(y_{t}\right)$, and $\log \left(p_{t}\right)$.

We compute the impulse response of $S_{t}$ to a monetary policy shock implied by (14) as follows. First, the shocks $u_{t}$ are regressed on the monetary-policy shock. Second, we compute the impact of a monetary-policy shock on $\log \left(r_{t}\right), \log \left(y_{t}\right), \log \left(p_{t}\right)$, and $\log \left(A_{t}\right)$. Figure 7 displays the associated impulse response functions for a one-standarddeviation shock to monetary policy. We see that an expansionary monetary policy shock is associated with a persistent rise in income and house prices as well as a decrease in average positive savings from refinancing.

Recall that our model abstracts from growth. To solve the model, we set the constant vector, $B_{0}$, in (14) to zero and work with the implied VAR for the level of the variables. This procedure is equivalent to estimating the VAR using data that have been demeaned. We approximate this VAR with a Markov chain using the procedure described in Appendix F. A key property of the Markov chain is that the implied impulse response functions to a monetary policy shocks are stationary.

\section{Empirical performance of the model}

We now compare our model with the data along a variety of dimensions. Model statistics are computed using simulated data generated as follows. We start the simulation in 1994, assuming that people have the distribution of assets, liabilities and mortgage rates observed in the data. We feed into the model the realized values of $\log \left(r_{t}\right), \log \left(y_{t}\right)$, and

$\log \left(p_{t}\right)$ for the period 1995-2007. We simulate the idiosyncratic component of income, $y_{j a t}$, for each household in our model. 
Given the estimated VAR, the housing Sharpe ratio implied by the model is $2.46 .{ }^{16}$ This value is similar to the Sharpe ratio implied by the NIPA Fixed Asset Tables 2.1, line 68 for the 1994-2007, which is 2.53 .

One possible concern is that our model abstracts from the idiosyncratic shocks to home prices emphasized by Landvoigt, Piazzesi, and Schneider (2015). Incorporating idiosyncratic risk into the model would greatly increase the computational complexity of our analysis. To assess the robustness of our results to more volatile house prices, we increase the volatility house-price shocks by 50 percent. Our main results regarding the state-dependent nature of monetary policy are robust to this perturbation. More volatile house prices make housing a riskier asset and deter home ownership. However, that volatility does not have a first-order effect on refinancing decision.

\subsection{Life-cycle dynamics.}

Consider the model's ability to account for how the behavior of U.S. households evolves with age. Figure 8 displays home-ownership rates, as well as the logarithm of nondurable consumption, the ratio of debt to net wealth, and household net wealth. The model does a reasonably good job at accounting for these moments of the data. Notably home ownership rates rise with age and stabilize when people reach their 40s, both in the model and the data.

To understand the mechanisms that underlie dynamics of home-ownership, it is useful to consider a simplified analysis of the cost of owning versus renting. ${ }^{17}$ The net benefit of owning a home is given by:

$$
\frac{p_{t}^{r}}{p_{t}}+E_{t} \frac{p_{t+1}-p_{t}}{p_{t}}-r_{t}\left(1-\frac{b_{t}}{p_{t}}\right)-\frac{b_{t}}{p_{t}} r_{t}^{m}-\delta-r_{t} \frac{\Phi^{\text {new }} h^{\text {own }}}{p_{t}} .
$$

The first term in equation (15) is the savings from not paying rent, which we express as a fraction of the house price, $p_{t}^{r} / p_{t}$. In our sample, $p_{t}^{r} / p_{t}$ is on average 7.7 percent.

\footnotetext{
${ }^{16}$ Returns to housing in the model are computed as $\log \left[\left(p_{t}^{r}+p_{t+1}-p_{t}\right) / p_{t}\right]$.

${ }^{17}$ See Diaz and Luengo-Prado (2012) for a review of the literature on the user cost of owning a home.
} 
The second term in this expression is the expected real rate of housing appreciation. In our calibration, $E_{t}\left(p_{t+1}-p_{t}\right) / p_{t}$ is on average one percent per year. The third term is the opportunity cost of the down payment, $1-b_{t} / p_{t}$ on a house. The fourth term is the mortgage payment on the house, where $r_{t}^{m}$ denotes the average mortgage rate. We estimate that the average value of $r_{t}$ and $r_{t}^{m}$ in our sample is 3.5 percent and 6.5 percent, respectively. The fifth term, $\delta$, is the rate of depreciation of the housing stock. We assume that $\delta$ is three percent per annum. The last term in equation (15) is the fixed cost of buying a house as a percentage of the house price. One difference between renting and buying not captured by equation (15) is that renters can freely vary the amount of housing services they purchase while home owners have to pay a fixed cost to change the size of their house.

A number of observations follow from equation (15). First, other things equal, the higher is the rental-price ratio and the expected real rate of housing appreciation, the more attractive it is to own rather than rent a house. Second, other things equal, the less expensive is the house (i.e. the lower is $p_{t}$ ) the larger is the negative impact of a fixed cost on the desirability of purchasing a home $\left(r_{t} \Phi^{\text {new }} h^{\text {own }} / p_{t}\right)$. Third, other things equal, the higher the down payment a household can make, the more attractive it is to own a home. To see this effect, it is convenient to rewrite the sum of the opportunity cost of the down payment and the mortgage payment, $r_{t}\left(1-b_{t} / p_{t}\right)+\left(b_{t} / p_{t}\right) r_{t}^{m}$ as:

$$
r_{t}+\frac{b_{t}}{p_{t}}\left(r_{t}^{m}-r_{t}\right) .
$$

The first term $\left(r_{t}\right)$, is the opportunity cost of purchasing a home without a mortgage. The second term, is the additional interest costs associated with buying a home with a mortgage of size $b$, which requires paying the spread $\left(r_{t}^{m}-r_{t}\right)$. From the second term, it is clear that, other things equal, the bigger is the mortgage the less desirable it is to buy a home.

With these observations as background, consider again Figure 8. The model implies that home ownership rates rise as people get older. This result follows from the fact 
that, on average, income rises as a person ages, peaking between 45 and 55 years of age. As income rises, people want to live in bigger homes, which reduces the impact of fixed costs on the desirability of purchasing a home $\left(r_{t} \Phi^{\text {new }} h^{\text {own }} / p_{t}\right)$. Also, as income rises, people can afford bigger down payments on those homes, which, as we just discussed, reduces the user cost of owning a home. Taken together, both forces imply that home ownership should on average rise until people are 55. Thereafter, home ownership rates roughly stabilize. However, many elderly homeowners downsize. They sell their old homes and use the proceeds to buy smaller homes which they eventually leave as bequests.

From Figure 8, we also see that household debt declines with age. This fact reflects two forces. First, people pay down their mortgages over time reducing their debt. Second, elderly people who are downsizing have small mortgages. Finally, household net wealth rises on average with age, as people pay off their mortgages and save for bequests.

Figure 8 also shows that non-durable consumption rises until people reach ages 45 to 55 and then falls. The rise results from two forces. First, people face borrowing constraints which prevent them from borrowing against future earnings. Second, most households have an incentive to save so they can make a down payment on their mortgage. The fall in non-durable consumption after age 55 reflects the presence of a bequest motive. As people age, the weight of expected utility from leaving bequests rises relative to the weight of utility from current consumption. When we reduce $B$, the parameter that controls the strength of the bequest motive, consumption becomes smoother.

\subsection{Refinancing and the interest-rate gap}

In the data, the average annual refinancing rate is 7.9 percent with a standard deviation of 4 percent. In the model, the average annual refinancing rate is 7.5. So, taking sampling uncertainty into account, the model does a good job of accounting for the average 
refinancing rate. The model is also consistent with the fraction of new mortgages issued in each period. ${ }^{18}$ This fraction is 25 percent both in the model and the data.

Figure 9 plots the fraction of loans that are refinanced as a function of the interestrate gap faced by people in the economy. We display these statistics both for the data and the model. The data-based statistics are computed as follows. We bin all the loans according to the interest-rate gap ranges indicated in the figure. For every bin, we calculate the fraction of loans that were refinanced. Figure 9 displays these fractions.

The model-based statistics are computed as follows. The initial distribution of age, assets, mortgage debt and mortgage rates is the same as the actual distribution in 1994. We assume there are 100, 000 households in the model economy and draw idiosyncratic shocks for each of these people. At each point in time, we feed in the actual values of the aggregate state of the economy from 1995 to 2007 for $r_{t}, y_{t}$, and $p_{t}$. We use the model to construct time series for $a_{t}$, the logarithm of economy-wide average positive savings from refinancing. People use this variable to form expectations for future aggregate states using the estimated version of equation (14). At every point in time, from 1995 to 2007, the model generates a distribution of interest-rate gaps and refinancing decisions. So, we are able to compute the same moments that we estimated from the data. As can be seen from Figure 9, the model does reasonably well at accounting for the data.

Andersen et al. (2015) and the references therein show that some agents do not refinance their fixed-rate mortgage when market rates fall below their locked-in mortgage rate. This phenomenon emerges more strongly at the top end of the rate gap. We could accommodate this "burnout" phenomenon by introducing heterogeneity in refinancing costs. However, this additional complexity seems unlikely to change our insights into the state-dependent nature of monetary policy because relatively few loans exhibit the burnout phenomenon. For example, the fraction of initial mortgages in our sample that

\footnotetext{
${ }^{18}$ New mortgages include refinancing of existing mortgages and mortgages issued to people who buy a new home. This pool of people includes people who were renters, new cohorts who enter the housing market, and people who upgrade or downgrade the size of their house.
} 
are never prepaid is 0.3 percent.

\subsection{State dependency of refinancing decisions}

We now assess the ability of the model to account for the state-dependent nature of the effects of monetary policy on refinancing decisions. Using data simulated from the model, we estimate the following regression using the monetary policy shock as instrument:

$$
\rho_{t+4}=\beta_{0}+\beta_{1} \Delta R_{t}^{M}+\beta_{2} \Delta R_{t}^{M} \times A_{j, t-1}+\beta_{3} A_{j, t-1}+\eta_{t}
$$

This regression is a version of regression (2) without county fixed effects. ${ }^{19}$ Table 7 , panel $\mathrm{A}$ reports the model-based and data-based estimates of $\beta_{1}$ and $\beta_{2}$. The data estimates are reproduced from panel A of Table 2. The model does quite well at accounting for the regression results. Taking sampling uncertainty into account, the model- and data-based estimates are not significantly different from each other.

Another way to assess the implications of the model is to calculate the effect of a 50 basis points reduction in the mortgage rate on the refinancing rate at each point in time. Our results are displayed in Figure 4 along with the regression-based estimates of these effects. Taking sampling uncertainty into account, the model does reasonably well at tracking the regression-based estimates. Even in periods where the model does less well, its implications are only a few basis points outside the confidence interval.

We also compute the time series of four cross-sectional moments for the interest rate gap in the data and the model: the top 25 percentile, the median, the mean, and the bottom 25 percentile. The time-series correlation between these moments in the model and the data is 75 percent, 60 percent, 85 percent, and 62 percent, respectively.

\footnotetext{
${ }^{19}$ To make the model regressions comparable with the data regressions we include a one-year lag of the refinancing rate.
} 


\subsection{State dependency of mortgages for new home purchases}

It is of interest to ask whether the model accounts for the response of purchases of new homes to an exogenous change in mortgage rates. To this end, we run a version of regression (2) on data simulated from the model. The dependent variable is the fraction of new mortgages used to purchase a new home relative to the number of outstanding mortgages. Table 7 , panel $\mathrm{C}$ reports our results. Both regression coefficients are statistically significant at the one-percent level. Also, there is strong evidence of state dependency in the response of new home purchases to changes in mortgage rates.

To interpret these coefficients, suppose that all the independent variables in the regression are initially equal to their time-series averages and that the average interestgap is initially equal to its mean value of -14 basis points. The estimates in column 1 of Panel $\mathrm{C}$ of Table 7 imply that a 25 basis points drop in mortgage rates raises the fraction of loans for new purchases by 3.5 percent. Now suppose that the drop in mortgage rates happens when the average interest-rate gap is equal to 56 basis points. Then, a 25 basis points drop in mortgage rates raises the fraction of loans for new purchases to 6.1 percent. So, the marginal impact of a one standard-deviation increase in the average interest-rate gap is 2.6 percent.

Column 2 of Table 7, panel $\mathrm{C}$ shows that the regression coefficients implied by our model are consistent with the empirical patterns discussed above. However, the model somewhat understates the direct impact of a change in mortgage rates and overstates the state dependency of new home purchases.

\subsection{Endogenous versus exogenous sources of state dependency}

Our model implies a non-linear representation of the data which involves state dependency. So, our theory compels us to estimate a VAR that allows for state dependency. The VAR which we use to compute agents' expectations is an exogenous source of state dependency. But the model embodies other strong, endogenous sources of state depen- 
dency. The most important of these sources is the presence of fixed costs of refinancing or getting a mortgage for a new home.

To substantiate these claims, we shut down the exogenous state-dependence in the VAR by setting the relevant coefficients to zero. We then re-solve the model using the resulting linear VAR and re-calculate the statistics reported in Table 7. The results are reported in column 3 of that Table. Consider the regression results for the fraction of loans that are refinanced. From panel A, we see that the coefficient on the interaction term $\left(\Delta R_{t} \times\right.$ Average Rate Gap) declines by roughly 40 percent. So, 40 percent of the state dependence comes from the VAR and 60 percent is generated endogenously by the model. Roughly similar results hold for the fraction of loans that are cash-refinanced (panel B) and the fraction of loans for home purchases (panel C). Taken together these results demonstrate that it is quantitatively important to allow for state dependency in the VAR. At the same time, most of the state dependency is endogenously generated by the structural model.

\section{Model implications}

In this section, we use our model to study the state-dependent effects of a fall in interest rates on consumption and how the potency of monetary policy depends on the past behavior of interest rates.

\subsection{State-dependent effects of a fall in interest rates on con- sumption}

We now use model-simulated data to estimate the effect of an exogenous change in the interest rate on the annual change in the logarithm of consumption for household $j$ $\left(c_{j t}\right)$ :

$$
c_{j t+1}-c_{j t}=\beta_{j 0}+\beta_{1} \Delta R_{t}^{M}+\beta_{2} \Delta R_{t}^{M} \times A_{t-1}+\beta_{3} A_{t-1}+\eta_{t}^{c} .
$$


The coefficients in this regression are estimated using the monetary shocks as instruments. Table 8 shows the effect of a 50 basis points fall in interest rates. The total effect on consumption of an exogenous change in mortgage rates is 2.84 percent. The direct effect $\left(\beta_{1} \Delta R_{t}^{M}\right)$ is 0.84 percent. The state dependent effect $\left(\beta_{2} \Delta R_{t}^{M} \times\right.$ average interest-rate gap) is 2.00 percent. ${ }^{20}$

To understand the mechanisms that underlie these effects, we estimate regression (18) for two separate groups: households that have positive liquid assets $\left(s_{j t}>0\right)$ and households that do not have positive liquid assets $\left(s_{j t} \leq 0\right)$. We call the first group of households unconstrained and the second group constrained. Forty percent of households are, on average, constrained in our model. This fraction is consistent with the results in Kaplan, Violante and Weidner (2014). More than 80 percent of the constrained households are home owners. These households correspond to what Kaplan, Violante and Weidner (2014) call wealthy hand-to-mouth consumers. The total effect on consumption of an exogenous change in mortgage rates is 4 and 0.63 percent for constrained and unconstrained households, respectively. So, the consumption response is predominantly driven by the constrained households. We obtain similar results when we define constrained (unconstrained) households as having less (more) liquid assets than two weeks of income.

Roughly 80 percent of the households who refinance engage in cash-out refinancing. This value is in line with the evidence presented by Chen, Michaux, and Roussanov (2020). Using a conservative estimate based on conforming mortgages, these authors argue that, over the period 1993-2010, on average about 70 percent of refinanced loans involve cash-out.

In response to a one-percent decline in mortgage rates, households who engage in cash-out refinancing in our model increase their loan balances by 27.7 percent. This

\footnotetext{
${ }^{20}$ Very little of the consumption response to mortgage rate changes is driven by the associated changes in house prices. We establish this result by computing the response of consumption to a change in mortgage rates keeping house prices constant. The implied consumption response is similar to that obtained when we do allow house prices to change.
} 
effect is broadly consistent with the empirical estimates of Bhutta and Keys (2016). ${ }^{21}$

To assess the model's implications for the state-dependent nature of cash-out refinancing, we use model-simulated data to estimate a version of regression (17) using monetary policy shocks as instruments. Here, the dependent variable is the fraction of total loans with cash-out refinancing. Our results are reported in Table 7, panel B. Comparing columns II in panels A and B, we see that in the data the state-dependent effect of an interest rate cut on refinancing and cash-out refinancing is about the same. The model captures, qualitatively, the state-dependent nature of cash-out refinancing, i.e. the larger are potential savings, the larger is the response of cash-out refinancing to an interest rate cut.

Our model abstracts from the effects of refinancing decisions on bank owners. If those owners are constrained and the profits of the bank rise or fall one to one by the amount that consumers save by refinancing, the refinancing channel has no aggregate effect on consumption. However, it is natural to assume that bank owners behave like unconstrained households. Under this assumption, the negative effect of refinancing on the consumption of bank owners is much smaller in absolute value than the positive effect on the consumption of constrained households. ${ }^{22}$ As a result, the overall effect of refinancing on aggregate consumption is positive. To explore the potential size of this effect we do a simple back-of-the-envelope calculation. We compute the change in consumption implied by a permanent-income-style calculation by multiplying the present value of total savings from refinancing by the steady-state risk-free rate (3.5 percent). We subtract this value from total consumption. This adjustment has a negligible impact with the growth rate of consumption falling by less than 0.01 percent.

It is possible that lenders respond to a fall in their income by reducing the flow of credit to borrowers. The precise way in which interest rates and the quantity of

\footnotetext{
${ }^{21}$ Using Equifax data, these authors estimate that, in response to a one-percent decline in mortgage rates, households who engage in cash-out refinancing increase their loan balances by 23 percent.

${ }^{22}$ The negative effect on U.S. consumption of the decline in profits due to refinancing is mitigated by the fact that some of stock shares of U.S. banks are owned by foreigners.
} 
credit change adjust depends on monetary policy, the nature of financial frictions and whether the economy is open or closed. For example, in an open economy like the U.S., international capital flows could adjust to compensate for any decline in the flow of credit from domestic lenders to domestic borrowers.

Finally, we do not explicitly model the wealth effects of duration risk on mortgage investors. This risk is embedded in the mortgage rates that we use to estimate equation (8). In solving the model, the mortgage rate that people face and their expectations of future mortgage rates reflect changes in the duration-risk premia arising from the state of the economy. So, even though we don't explain those premia, we do account for them when solving the model.

\subsubsection{The importance of life-cycle dynamics}

Life-cycle dynamics play an important role in our quantitative results. To illustrate this role, we consider an alternative version of the model with no income life-cycle dynamics. Unlike in our benchmark model, young people have no systematic incentive to borrow against future income. As a result, mortgage balances are smaller and fewer people are financially constrained. So, the gains from refinancing are smaller.

In this alternative economy, both the direct and state-dependent effect of monetary policy on refinancing are smaller. The direct effect of a change in mortgage rates

as measured by $\beta_{1}$ (the coefficient on $\Delta R_{t}^{M}$ in equation (2)) drops from 0.06 in the benchmark model to roughly zero. The state dependent effect as measured by $\beta_{2}$ (the coefficient on $\Delta R_{t}^{M} \times$ average interest-rate gap in equation (2)) drops from 0.232 to 0.088. We obtain similar results for the fraction of loans that are cash-out refinanced.

\subsection{State dependency and the potency of monetary policy}

In this subsection, we provide intuition for the state-dependent effects of monetary policy in our model by comparing the impact of a given interest rate cut in different 
scenarios. We then use our model to quantify an important cost of prolonged lowinterest rate periods.

\subsubsection{Model experiments}

In all of the experiments considered in the subsection the model economy starts in steady state, i.e. the aggregate state variables have been constant and equal to their unconditional means. However, people have been experiencing ongoing idiosyncratic shocks to their income.

The three paths that we consider are displayed in Figure 10. At each point in time, people form expectations about aggregate states according to the Markov-chain approximation to the demeaned level representation of the aggregate states associated with (14). Our results are summarized in Panel A of Table 9.

In the first scenario, we consider the effect of an interest rate cut when the economy starts in steady state and remains there until period four. In period five, we feed an interest-rate shock into the model that generates a 50-basis point fall in the interest rate. We refer to this scenario as the benchmark scenario. From row (i) of Table 9, Panel A we see that 16 percent of people refinance in the impact period of the shock and aggregate consumption increases 1.7 percent. There are two reasons why these effects are so large. First, all existing homeowners with a mortgage have a positive rate gap after the interest rate cut because they obtained their mortgages at the steady-state mortgage interest rate. Second, people expect the interest rate to revert to the mean, so period seven is a good time to refinance.

In the second scenario, the central bank steadily raises interest rates starting in period one until they peak in period four. The central bank then cuts the interest rate by 50 basis points in period five. From row (ii) of Table 9, Panel A we see that only 9 percent of households refinance in the impact period of the shock and there is only a 0.3 percent rise in consumption. The reason for these small effects is that only 31 percent of people face a positive interest-rate gap in period five. These are the people 
who entered new mortgages despite rising interest rates due to life-cycle considerations or idiosyncratic income shocks.

In the third scenario, the central bank steadily lowers interest rates starting in period one until they trough in period four. The central bank then cuts interest rates by 50 basis points in period five. From row (ii) of Table 9, Panel B we see that in this scenario, 13 percent of people refinance in the impact period of the shock and there is a 0.6 percent rise in consumption. The consumption effect is smaller than in the first scenario because a subset of people refinanced as interest rates declined and engaged in cash-out refinancing. Those people are generally not liquidity constrained in period seven. $^{23}$

These results show that, in our model, the current impact of monetary policy through the refinancing channel depends on the past actions of the Fed. The fundamental reason is that those actions affect the distribution of potential savings from refinancing.

\subsubsection{A downside of long periods of low interest rates}

Here we use our model to quantify an important cost of keeping interest rates low for a long period of time: it makes monetary policy less powerful for an extended period thereafter.

We begin by addressing the question: after rates have been normalized, when does monetary policy regain its initial potency? To address this question we consider the paths displayed in Figure 11. In all of these cases, the economy starts from steady state and the interest rate falls from 3.5 percent to 1 percent for four periods. The interest rate then normalizes back to 3.5 percent. The difference between the cases is that $t$ periods after the normalization, $t \in\{1,2,3\}$, the interest rate falls by 50 basis points.

Results are reported in Table 10. From this table we see that aggregate consumption

\footnotetext{
${ }^{23}$ The average interest rate is a key determinant of when households refinance. When they do so, it is often optimal to take advantage of the new loan and cash out. Because of the fixed costs of refinancing, it is not in general optimal to refinance just to cash out.
} 
rises by $0.8,0.8$ and 2.3 percent for $t=1,2$, and 3 , respectively. So the sooner the interest rate cut after normalization occurs, the smaller is its impact. For reference, recall that aggregate consumption rises by 1.7 percent if the interest rate falls by 50 basis points in the benchmark scenario where the economy is in steady state. So, the potency of an interest rate cut is substantially reduced for the first two years after the interest rate is normalized.

The key factor driving this result is that fewer people face a positive interest-rate gap when the interest rate is cut relative to the benchmark scenario. Many people face a negative-rate gap because they entered mortgages at rates that were lower than the steady-state mortgage rate. So fewer people have an incentive to refinance their mortgages in period seven than in the benchmark scenario.

Over time, people enter new loans in response to life-cycle-related income changes and idiosyncratic-income shocks. So, the share of people with a mortgage rate equal to the steady-state rate increases over time. That increase in turn implies that a larger fraction of people have a positive-rate gap after a 50 basis points rate cut. The potency of an interest rate cut rises over time. According to Table 10, it takes roughly three years for monetary policy to have the same effect on consumption as in the benchmark case.

Consistent with the post-normalization results, our model also implies that monetary policy is less potent when interest rates are low. To illustrate this point, suppose that starting from steady state, the interest rate falls from 3.5 percent to 1 percent for five periods. ${ }^{24}$ Then, in period seven, the interest rate falls by an additional 50 basis points (not shown on the Figure). According to our model, only 5 percent of people refinance in the impact period of the shock and there is only a 0.8 percent rise in consumption. These modest effects contrast sharply with the effect of an interest rate fall

\footnotetext{
${ }^{24}$ As above, we model changes in interest rates via sequences of interest rate shocks. In all cases, agents form expectations about aggregate states according to the Markov-chain approximation to the demeaned level representation of the aggregate states associated with equation (14).
} 
in the benchmark scenario where 16 percent of people refinance in the impact period of the shock and there is a 1.7 percent rise in consumption.

What can policy makers do to deal with the potency problem? One possibility is to take advantage of the nonlinear response of consumption to a fall in the interest rate. Recall that a 50 basis point interest rate cut in the first period after interest rates normalize leads to a 1.7 percent rise in consumption. Suppose instead that the interest rate fell by 100 basis points. Then consumption would rise by 2.8 percent. This increase is roughly the same if, starting from steady state, the interest rate falls by 100 basis.

These results suggest that policy makers can deal with the potency problem in one of two ways. If they cut interest rates by relatively small amounts, e.g. 50 basis points, then they wait until policy regains the same impact as in the steady state. However, if they are prepared to cut interest rates by large amounts, e.g. 100 basis points, the potency problem is not an issue as long as monetary policy is not constrained by the effective lower bound (ELB).

There is considerable debate about the importance of the ELB. For example, Debortoli, Gali, and Gambetti (2020) argue that the ELB was not a binding constraint in the aftermath of the financial crises. The conventional view (e.g. Eggertsson (2003), Eggertsson and Woodford (2004), and Christiano, Eichenbaum and Rebelo (2011)) is that the ELB does constrain monetary policy. Swanson and Williams (2014) argue that the ELB was not binding before 2011 but did constrain monetary policy thereafter. Kiley and Roberts (2017) argue that the ELB will be binding 30 to 40 percent of the time in the future. To the extent that the ELB is a constraint on monetary policy, it would be difficult for the Fed to lower rates by large amounts after a prolonged period of low interest rates. 


\section{Conclusion}

This paper provides evidence that the efficacy of monetary policy is state dependent, varying in a systematic way with the pool of savings from refinancing. We construct a quantitative life-cycle model of refinancing decisions that is consistent with the facts that we document.

Our model points to an important cost of fighting recessions with a prolonged period of low interest rates. Such a policy reduces the potency of monetary policy in the period after interest rates are normalized. So, if the economy is affected by a negative shock during that period, policy makers will have less ammunition at their disposal to counteract the effects of that shock. This observation raises the conundrum: should monetary policy makers use their ammunition to fight an ongoing recession or the next one?

\section{References}

Agarwal, Sumit, John Driscoll, and David Laibson, 2013, "Optimal Mortgage Refinancing: A Closed Form Solution," Journal of Money, Credit, and Banking 45, 591-622.

Andersen, S., Campbell J., Nielsen K., and Ramadorai T. "Inattention and Inertia in Household Finance: Evidence from the Danish Mortgage Market," National Bureau of Economic Research working paper No. 21386, 2015.

Auclert, Adrien "Monetary Policy and the Redistribution Channel," manuscript, Stanford University, 2017.

Beraja, Martin, Andreas Fuster, Erik Hurst, and Joseph Vavra "Regional Heterogeneity and the Refinancing Channel of Monetary Policy," Quarterly Journal of Economics, 2018.

Berger, David, Guerrieri, Veronica, Lorenzoni, Guido and Vavra, Joseph, 2017. "House Prices and Consumer Spending." The Review of Economic Studies, 85(3), pp.1502-1542. 
Berger, David, Konstantin Milbradt, Fabrice Tourre, and Joseph Vavra (2018), "Mortgage Prepayment and Path-Dependent Effects of Monetary Policy," manuscript, Northwestern University.

Bhutta, Neil and Benjamin J. Keys. 2016. "Interest Rates and Equity Extraction during the Housing Boom." American Economic Review 106 (7):1742-1774.

Chen, Hui, Michael Michaux, and Nikolai Roussanov. "Houses as ATMs: mortgage refinancing and macroeconomic uncertainty." The Journal of Finance 75, no. 1 (2020): 323-375.

Christiano, Lawrence, Martin Eichenbaum, and Sergio Rebelo. "When is the Government Spending Multiplier Large?.” Journal of Political Economy 119, no. 1 (2011): $78-121$.

Cochrane, John H., and Monika Piazzesi. "The fed and interest rates-a highfrequency identification." American Economic Review 92, no. 2 (2002): 90-95.

Debortoli, Davide, Jordi Gali-, and Luca Gambetti. "On the Empirical (Ir) relevance of the Zero Lower Bound Constraint." NBER Macroeconomics Annual 34, no. 1 (2020): 141-170.

DeFusco, Anthony A. and John Mondragon "No Job, No Money, No Refi: Frictions to Refinancing in a Recession," manuscript, Northwestern University, 2018.

De Nardi, Mariacristina and Fang Yang "Bequests and Heterogeneity in Retirement Wealth," European Economic Review, Elsevier, vol. 72(C), pages 182-196, 2014.

Di Maggio, Marco, Amir Kermani, Benjamin J. Keys, Tomasz Piskorski, Rodney Ramcharan, Amit Seru, and Vincent Yao. "Interest Rate Pass-through: Mortgage rates, Household Consumption, and Voluntary Deleveraging." American Economic Review 107, no. 11 (2017): 3550-88.

Diaz, Antonia, and J. Luengo-Prado, Maria. 2012. "The user cost, home ownership and housing prices: Theory and evidence from the US." International Encyclopedia of Housing and Home, 228-234.

Diaz, Antonia and Maria J. Luengo-Prado "The User Cost, Home Ownership and 
Housing Prices: Theory and Evidence from the U.S." in Smith, S.J.; Elsinga, M.; Fox-O'Mahony, L.; Ong, S.E.; Wachter, S. (editors) The International Encyclopedia of Housing and Home, Elsevier (2012).

Diep, Peter, Andrea L. Eisfeldt, Scott Richardson, 2017, "Prepayment Risk and Expected MBS Returns," NBER Working Paper No. 22851

Doepke, Matthias, and Martin Schneider. "Inflation and the Redistribution of Nominal Wealth." Journal of Political Economy 114, no. 6 (2006): 1069-1097.

Doepke, Matthias, Martin Schneider, and Veronika Selezneva. "Distributional Effects of Monetary Policy," manuscript, Northwestern University, 2018.

Dunn, Kenneth B., and John J. McConnell. "Valuation of GNMA Mortgage-backed Securities." The Journal of Finance 36, no. 3 (1981): 599-616.

Eggertsson, Gauti B. "Zero Bound on Interest Rates and Optimal Monetary Policy," Brookings papers on economic activity 2003, no. 1 (2003): 139-233.

Eggertsson, Gauti B., and Michael Woodford. "Policy Options in a Liquidity Trap. "American Economic Review 94, no. 2 (2004): 76-79.

Garriga, C. and Hedlund, A., 2017. Mortgage Debt, Consumption, and Illiquid Housing Markets in the Great Recession. FRB St. Louis Working Paper, (2017-30).

Garriga, Carlos, Finn E. Kydland, and Roman Šustek. "Mortgages and monetary policy." The Review of Financial Studies 30, no. 10 (2017): 3337-3375.

Gertler, Mark, and Peter Karadi. "Monetary Policy Surprises, Credit Costs, and Economic Activity." American Economic Journal: Macroeconomics 7.1 (2015): 44-76.

Gilchrist, Simon, David López-Salido, and Egon Zakrajšek. "Monetary policy and real borrowing costs at the zero lower bound." American Economic Journal: Macroeconomics 7, no. 1 (2015): 77-109.

Gorodnichenko, Yuriy, and Michael Weber. "Are Sticky Prices Costly? Evidence from the Stock Market." American Economic Review 106, no. 1 (2016): 165-99.

Green, Jerry, and John B. Shoven. 1986. The Effects of Interest Rates on Mortgage Prepayments. Journal of Money, Credit and Banking 18, no. 1: 41-59. 
Greenwald, Daniel "The Mortgage Credit Channel of Macroeconomic Transmission," manuscript, Sloan School of Management, MIT, 2016.

Guren, A.M., Krishnamurthy, A. and McQuade, T.J., 2018. Mortgage Design in an Equilibrium Model of the Housing Market (No. w24446). National Bureau of Economic Research.

Guren, A.M., McKay, A., Nakamura, E. and Steinsson, J., 2018. Housing Wealth Effects: The Long View (No. w24729). National Bureau of Economic Research.

Gürkaynak, Refet S., Brian Sack, and Eric Swanson. "The Sensitivity of Longterm Interest Rates to Economic News: Evidence and Implications for Macroeconomic Models." American Economic Review 95, no. 1 (2005): 425-436.

Guvenen, Fatih, and Anthony A. Smith. 2014. "Inferring Labor Income Risk and Partial Insurance from Economic Choices." Econometrica, 82(6): 2085-2129.

Guvenen, Fatih, Fatih Karahan, Serdar Ozkan, and Jae Song. 2015. "What Do Data on Millions of U.S. Workers Reveal about Life-Cycle Earnings Risk?" National Bureau of Economic Research Working Paper 20913.

Huggett, Mark, "Wealth Distribution in Life-cycle Economies", Journal of Monetary Economics, Volume 38, Issue 3, December 1996, Pages 469-494.

Hurst, Erik, Keys, Benjamin, Seru, Amit and Vavra, Joseph, "Regional Redistribution Through the U.S. Mortgage Market", American Economic Review, 2016, 106(10), 2982-3028.

Iacoviello, M., 2005. House Prices, Borrowing Constraints, and Monetary Policy in the Business Cycle. American Economic Review, 95(3), pp.739-764.

Iacoviello, M. and Pavan, M., 2013. Housing and Debt over the Life Cycle and Over the Business Cycle. Journal of Monetary Economics, 60(2), pp.221-238.

Khandani, Amir E., Andrew W. Lo, and Robert C. Merton, 2013, "Systemic Risk and the Refinancing Ratchet Effect", Journal of Financial Economics 108, 29-45.

Kaplan, Greg, Kurt Mitman and Giovanni L. Violante "The Housing Boom and Bust: Model Meets Evidence," manuscript, Princeton University, 2017. 
Kaplan, Greg, Benjamin Moll and Gianluca Violante "Monetary Policy According to HANK," American Economic Review, 108(3), 697-743, 2018.

Kaplan, Greg and Giovanni L. Violante \& Justin Weidner, 2014. "The Wealthy Hand-to-Mouth," Brookings Papers on Economic Activity, vol 2014(1), pages 77-138.

Kiley, Michael T., and John M. Roberts. " Monetary Policy in a Low Interest Rate World."Brookings Papers on Economic Activity 2017, no. 1 (2017): 317-396.

Kuttner, Kenneth N. "Monetary Policy Surprises and Interest Rates: Evidence from the Fed Funds Futures Market." Journal of Monetary Economics 47, no. 3 (2001): 523544 .

LaCour-Little, Michael. "The Evolving Role of Technology in Mortgage Finance." Journal of Housing Research (2000): 173-205.

Landvoigt, Tim, Monika Piazzesi, and Martin Schneider. 2015. "The Housing Market(s) of San Diego." American Economic Review, 105(4): 1371-1407.

McKay, A., Nakamura, E. and Steinsson, J., 2016. "The Power of Forward Guidance Revisited," American Economic Review, 106(10), pp.3133-58.

Mian Atif, Kamelesh Rao and Amir Sufi "Household Balance Sheets, Consumption, and the Economic Slump" Quarterly Journal of Economics, 2013, 1687-1726

Mian, Atif, and Amir Sufi. 2014. "House Price Gains and U.S. Household Spending from 2002 to 2006." National Bureau of Economic Research, Inc NBER Working Papers 20152.

Nakamura, Emi and Jón Steinsson "High Frequency Identification of Monetary NonNeutrality: The Information Effect. " Quarterly Journal of Economics, 133(3), 12831330, August 2018.

Piazzesi, M. and M. Schneider (2016): "Housing and Macroeconomics," Handbook of Macroeconomics, 2, 1547-1640.

Rios-Rull, J.V. and Sanchez-Marcos, V., 2008 "An Aggregate Economy with Different Size Houses," Journal of the European Economic Association, 6(2-3), pp.705-714.

Scharfstein, David and Adi Sunderam, "Market Power in Mortgage Lending and 
the Transmission of Monetary Policy," 2013 NBER working paper 19156.

Schwartz, Eduardo S. and Walter N. Torous 1989. "Prepayment and the Valuation of Mortgage-Backed Securities." Journal of Finance 44(2), pp. 375-392.

Stock, James H., and Motohiro Yogo. 2005. Testing for Weak Instruments in Linear IV regression. In Identification and Inference for Econometric Models: Essays in Honor of Thomas Rothenberg, ed. D. W. K. Andrews and J. H. Stock, 80-108. New York: Cambridge University Press.

Swanson, Eric T., and John C. Williams. "Measuring the Effect of the Zero Lower Bound on Medium-and Longer-Term Interest Rates." American Economic Review 104, no. 10 (2014): 3154-85.

Woodford, M., 2012 "Methods of Policy Accommodation at the Interest-rate Lower Bound." In Proceedings-Economic Policy Symposium-Jackson Hole (pp. 185-288). Federal Reserve Bank of Kansas City.

Wong, Arlene. 2020 "Population Aging and the Transmission of Monetary Policy to Consumption," manuscript, Princeton University. 


\section{Tables and Figures}

Table 1: First-stage estimates

\begin{tabular}{lcc}
\hline First stage y-variable: & $\Delta \mathbf{R}(\mathrm{t})$ & $\Delta \mathbf{R}(\mathrm{t}) \times \mathrm{A}(\mathrm{t}-\mathbf{1})$ \\
& $(\mathrm{I})$ & $(\mathrm{II})$ \\
\hline & & \\
$\varepsilon(\mathrm{t})$ & $0.613^{* * *}$ & $0.197^{* * *}$ \\
& $(0.006)$ & $(0.007)$ \\
$\varepsilon(\mathrm{t}) \times$ Average rate gap & $0.135^{* * *}$ & $0.109^{* * *}$ \\
& $(0.009)$ & $(0.011)$ \\
\hline F-statistic & 4,511 & 434 \\
\hline
\end{tabular}

Notes: Regression equation (2), first-stage estimates based on futures shock. Standard errors are in parentheses. ${ }^{*},{ }^{* *}$, and ${ }^{* *}$ give the significance at the 10,5 , and 1 percent levels. 
Table 2: State dependency of monetary policy and refinancing

\begin{tabular}{lc}
\hline & $(\mathrm{l})$ \\
\hline Panel A: Fraction refinanced & 0.040 \\
$\Delta \mathrm{R}(\mathrm{t})$ & $(0.023)$ \\
& $0.266^{* * *}$ \\
$\Delta \mathrm{R}(\mathrm{t}) \times$ Average rate gap & $(0.076)$ \\
& \\
Panel B: Fraction cash-out refinanced & $0.074^{* * *}$ \\
$\Delta \mathrm{R}(\mathrm{t})$ & $(0.007)$ \\
& $0.176^{* * *}$ \\
$\Delta \mathrm{R}(\mathrm{t}) \times$ Average rate gap & $(0.027)$ \\
& \\
Panel C: Change in balance, given cash-out refinance & $0.237^{* * *}$ \\
$\Delta \mathrm{R}(\mathrm{t})$ & $(0.026)$ \\
& $0.215^{*}$ \\
$\Delta \mathrm{R}(\mathrm{t}) \times$ Average rate gap & $(0.132)$ \\
& \\
\hline County Fixed Effects & Yes \\
SPF Controls & Yes \\
Additional county controls & Yes \\
\hline
\end{tabular}

Notes: The table reports the response to a decline in interest rates. It therefore reports the estimates from regression equation (2), multiplied by -1 . The IV is based on futures. Standard errors are in parentheses. ${ }^{*},{ }^{* *}$, and ${ }^{* * *}$ give the significance at the 10,5 , and 1 percent levels. 
Table 3: State dependency of monetary policy, unemployment and housing permits

\begin{tabular}{lcc}
\hline & $\begin{array}{c}\text { Change in unemployment } \\
\text { rate over the year }\end{array}$ & $\begin{array}{c}\text { Housing permit growth } \\
\text { over the year }\end{array}$ \\
& $(\mathrm{I})$ & (II) \\
\hline $\mathrm{R}(\mathrm{t})$ & $-0.034^{*}$ & $0.248^{* * *}$ \\
& $(0.014)$ & $(0.043)$ \\
$\Delta \mathrm{R}(\mathrm{t}) \times$ Average rate gap & $-0.065^{* * *}$ & $0.234^{* * *}$ \\
& $(0.014)$ & $(0.087)$ \\
\hline County Fixed Effects & & Yes \\
SPF Controls & Yes & Yes \\
Additional county controls & Yes & Yes \\
\hline
\end{tabular}

Notes: The table reports the response to a decline in interest rates. It therefore reports the estimates from regression equations (4) and (5), multiplied by -1. IV is based on futures. Standard errors are in parentheses. ${ }^{*},{ }^{* *}$, and ${ }^{* *}$ give the significance at the 10,5 , and 1 percent levels.

Table 4: Model parameter values

\begin{tabular}{llc}
\hline Parameters & Value \\
\hline$\sigma$ & Coefficient of relative risk aversion & 2 \\
$\delta$ & Housing depreciation rate & $3 \%$ \\
$\phi$ & Collateral constraint & 0.2 \\
$\rho_{\eta}$ & Persistency of idiosyncratic income process & 0.91 \\
$\sigma_{\eta}$ & Variance of idiosyncratic income shock & 0.21 \\
$\alpha$ & Utility parameter & 0.88 \\
$\beta$ & Discount rate & 0.962 \\
B & Bequest parameter & 2 \\
\hline
\end{tabular}

Notes: Table depicts parameter values. See text for more detail. 
Table 5: Estimated Aggregate Process for Mortgage and Rental Rates

\begin{tabular}{lcc}
\hline & \multicolumn{2}{c}{ Regression with dependent variable } \\
Variables & 30-year rate & log rental rate ${ }_{\mathrm{t}}$ \\
\hline $\log \mathrm{y}_{\mathrm{t}}$ & $-3.475^{* * *}$ & $0.843^{* * *}$ \\
& $(0.168)$ & $(0.119)$ \\
$\log \mathrm{r}_{\mathrm{t}}$ & $0.334^{* * *}$ & $-0.002^{* * *}$ \\
& $(0.058)$ & $(0.001)$ \\
$\log \mathrm{p}_{\mathrm{t}}$ & & -0.022 \\
& & $(0.014)$ \\
constant & -0.030 & $3.187^{* * *}$ \\
& $(15.82)$ & $(0.488)$ \\
\hline
\end{tabular}

Notes: Standard errors are in parentheses. ${ }^{*},{ }^{* *}$, and ${ }^{* * *}$ give the significance at the 10,5 , and 1 percent levels. These are the estimated coefficients for equations (8) and (9). See text for more detail.

Table 6: Estimated Aggregate Process

\begin{tabular}{lcccc}
\hline \multirow{2}{*}{ Variables } & \multicolumn{4}{c}{ Regression with dependent variable } \\
& $\log y_{\mathrm{t}}$ & $\log \mathrm{r}_{\mathrm{t}}$ & $\log \mathrm{p}_{\mathrm{t}}$ & $\log$ savings \\
\hline $\log \mathrm{y}_{\mathrm{t}-1}$ & $-0.272^{* *}$ & $0.401^{* * *}$ & -0.006 & -2.715 \\
& $(0.108)$ & $(2.845)$ & $(0.047)$ & $(0.147)$ \\
$\log \mathrm{r}_{\mathrm{t}-1}$ & 0.071 & $0.900^{* * *}$ & $0.295^{* * *}$ & 12.130 \\
& $(0.108)$ & $(0.051)$ & $(0.002)$ & $(0.147)$ \\
$\log \mathrm{p}_{\mathrm{t}-1}$ & $0.119^{*}$ & 0.055 & $0.788^{* * *}$ & 1.177 \\
& $(0.075)$ & $(2.114)$ & $(0.070)$ & $(1.710)$ \\
$\log$ savings & 0.001 & -0.002 & $0.011^{* * *}$ & $0.457^{*}$ \\
& $(0.006)$ & $(0.142)$ & $(0.008)$ & $(0.296)$ \\
$\log$ savings & -0.073 & $-0.187^{* * *}$ & $-0.269 * * *$ & $-8.880 * *$ \\
& $(0.002)$ & $(0.035)$ & $(0.002)$ & $(0.086)$ \\
\hline
\end{tabular}

Notes: Regression equation (15). Standard errors are in parentheses. ${ }^{*},{ }^{* *}$, and ${ }^{* * *}$ give the significance at the 10,5 , and 1 percent levels. See text for more detail. 
Table 7: State dependency of monetary policy and refinancing: Model vs Data

\begin{tabular}{|c|c|c|c|}
\hline & \multirow[t]{2}{*}{ Data } & \multicolumn{2}{|c|}{ Model } \\
\hline & & Benchmark & $\begin{array}{c}\text { No state- } \\
\text { dependency } \\
\text { in VAR }\end{array}$ \\
\hline \multicolumn{4}{|c|}{ Panel A: Fraction of loans that refinanced } \\
\hline$\Delta \mathrm{R}(\mathrm{t})$ & $\begin{array}{c}0.040 * * * \\
(0.023)\end{array}$ & 0.060 & 0.103 \\
\hline$\Delta \mathrm{R}(\mathrm{t}) \times$ Average rate gap & $\begin{array}{c}0.266^{* * *} \\
(0.076)\end{array}$ & 0.232 & 0.139 \\
\hline \multicolumn{4}{|c|}{ Panel B: Fraction of loans that are cash-out refi } \\
\hline$\Delta \mathrm{R}(\mathrm{t})$ & $\begin{array}{c}0.074^{* * *} \\
(0.007)\end{array}$ & 0.061 & 0.103 \\
\hline$\Delta R(t) \times$ Average rate gap & $\begin{array}{c}0.176 * * * \\
(0.027)\end{array}$ & 0.232 & 0.139 \\
\hline \multicolumn{4}{|c|}{ Panel C: Fraction of loans for home purchases } \\
\hline$\Delta \mathrm{R}(\mathrm{t})$ & $\begin{array}{c}0.162 * * * \\
(0.014)\end{array}$ & 0.120 & 0.067 \\
\hline$\Delta \mathrm{R}(\mathrm{t}) \times$ Average rate gap & $\begin{array}{c}0.147^{* * *} \\
(0.019)\end{array}$ & 0.160 & 0.077 \\
\hline
\end{tabular}

Notes: The table reports the response to a decline in interest rates. It therefore reports the estimates from regression equation (2), multiplied by -1 . Standard errors are in parentheses. ${ }^{*},{ }^{* *}$, and ${ }^{* * *}$ give the significance at the 10,5 , and 1 percent levels. 
Table 8: State dependency of monetary policy

\begin{tabular}{cc}
\hline Effect on refinancing: & \\
Overall effect of a 50 bp expansionary shock & $4.63 \%$ \\
$\beta_{1} \Delta \mathrm{R}_{\mathrm{t}}$ & $2.99 \%$ \\
$\beta_{2} \Delta \mathrm{R}_{\mathrm{t}}$ times mean $\left(\varphi_{\mathrm{t}}\right)$ & $1.65 \%$ \\
Effect on consumption: & \\
Overall effect of a 50 bp expansionary shock & $2.84 \%$ \\
$\beta_{1} \Delta \mathrm{R}_{\mathrm{t}}$ & $0.84 \%$ \\
$\beta_{2} \Delta \mathrm{R}_{\mathrm{t}}$ times mean $\left(\varphi_{\mathrm{t}}\right)$ & $2.00 \%$ \\
\hline
\end{tabular}

Notes: The table reports the response to a decline in interest rates. It therefore reports the estimates from regression equation (2), multiplied by -1 . See text for more detail.

Table 9: Alternative paths of monetary policy

\begin{tabular}{lccccc}
\hline Rate path prior to a 50bp cut & $\begin{array}{c}\text { Average } \\
\text { rate gap } \\
\text { before cut }\end{array}$ & $\begin{array}{c}\text { Fraction with } \\
\text { positive rate gap, } \\
\text { after rate cut }\end{array}$ & $\begin{array}{c}\text { Effect on } \\
\text { refinancing }\end{array}$ & $\begin{array}{c}\text { Change in } \\
\text { consumption }\end{array}$ & $\begin{array}{c}\text { Fraction ST } \\
\text { constrained }\end{array}$ \\
\hline Panel A: Effects of Flat vs Rising History & & & & & \\
(i) Flat at about 3.5\% & $0.00 \%$ & $100 \%$ & $16 \%$ & $1.7 \%$ & 0.68 \\
(ii) Rising from 3.5\% to 6.5\% over 4 pds & $-0.60 \%$ & $31 \%$ & $9 \%$ & $0.3 \%$ & 0.72 \\
Difference (i)-(ii) & $0.60 \%$ & $69 \%$ & $7 \%$ & $1.4 \%$ & -0.04 \\
& & & & & \\
Panel B: Effects of Flat vs Falling History & & & & & \\
(i) Flat at about 3.5\% & $0.00 \%$ & $100 \%$ & $16 \%$ & $1.7 \%$ & 0.68 \\
(ii) Falling from 3.5\% to 1\% over 4 pds & $0.44 \%$ & $100 \%$ & $13 \%$ & $0.6 \%$ & 0.60 \\
Difference (i)-(ii) & $-0.44 \%$ & $0 \%$ & $3 \%$ & $1.1 \%$ & 0.08 \\
\hline
\end{tabular}

Notes: Alternative paths of monetary policy. See text for more detail. 
Table 10: Alternative paths of monetary policy

\begin{tabular}{|c|c|c|c|c|c|}
\hline Rate path prior to a rate cut & $\begin{array}{l}\text { Average } \\
\text { rate gap } \\
\text { before cut }\end{array}$ & $\begin{array}{l}\text { Fraction with } \\
\text { positive rate } \\
\text { gap, after } \\
\text { rate cut }\end{array}$ & $\begin{array}{l}\text { Effect on } \\
\text { refinancing }\end{array}$ & $\begin{array}{l}\text { Change in } \\
\text { consumption }\end{array}$ & $\begin{array}{l}\text { Fraction ST } \\
\text { constrained }\end{array}$ \\
\hline \multicolumn{6}{|l|}{ Reloading Effect with 50bp cut } \\
\hline $\begin{array}{l}\text { (a) Benchmark case: continuously flat at } \\
3.5 \% \text { prior to a } 50 \mathrm{bp} \text { rate cut }\end{array}$ & $0.00 \%$ & $100 \%$ & $16 \%$ & $1.7 \%$ & $68 \%$ \\
\hline $\begin{array}{l}\text { (b) } 3.5 \% \text { cut to } 1 \% \text { for } 4 \text { pds, rise for } 3 \text { pds } \\
\text { to } 3.5 \% \text {, flat at } 3.5 \% \text { for } 1 \text { pd }\end{array}$ & $-0.19 \%$ & $87 \%$ & $5 \%$ & $0.8 \%$ & $69 \%$ \\
\hline $\begin{array}{l}\text { (c) } 3.5 \% \text { cut to } 1 \% \text { for } 4 \mathrm{pds} \text {, rise for } 3 \mathrm{pds} \\
\text { to } 3.5 \% \text {, flat at } 3.5 \% \text { for } \mathbf{2} \text { pds }\end{array}$ & $-0.11 \%$ & $89 \%$ & $6 \%$ & $0.8 \%$ & $72 \%$ \\
\hline $\begin{array}{l}\text { (d) } 3.5 \% \text { cut to } 1 \% \text { for } 4 \text { pds, rise for } 3 \text { pds } \\
\text { to } 3.5 \% \text {, flat at } 3.5 \% \text { for } 3 \text { pds }\end{array}$ & $-0.09 \%$ & $89 \%$ & $19 \%$ & $2.3 \%$ & $72 \%$ \\
\hline \multicolumn{6}{|l|}{ Reloading Effect with 100bp cut } \\
\hline $\begin{array}{l}\text { (e) Benchmark case: continuously flat at } \\
3.5 \% \text { prior to a } 100 \mathrm{bp} \text { rate cut }\end{array}$ & $0.00 \%$ & $100 \%$ & $19 \%$ & $2.8 \%$ & $73 \%$ \\
\hline $\begin{array}{l}\text { (f) } 3.5 \% \text { cut to } 1 \% \text { for } 4 \mathrm{pds} \text {, rise for } 3 \mathrm{pds} \\
\text { to } 3.5 \% \text {, flat at } 3.5 \% \text { for } 1 \text { pd }\end{array}$ & $-0.19 \%$ & $87 \%$ & $18 \%$ & $2.8 \%$ & $70 \%$ \\
\hline
\end{tabular}

Notes: Alternative paths of monetary policy. See text for more detail. 
Figure 1: Time Series of the Refinancing Rate

(a) Refinancing Rate

Level of Refinancing Rate

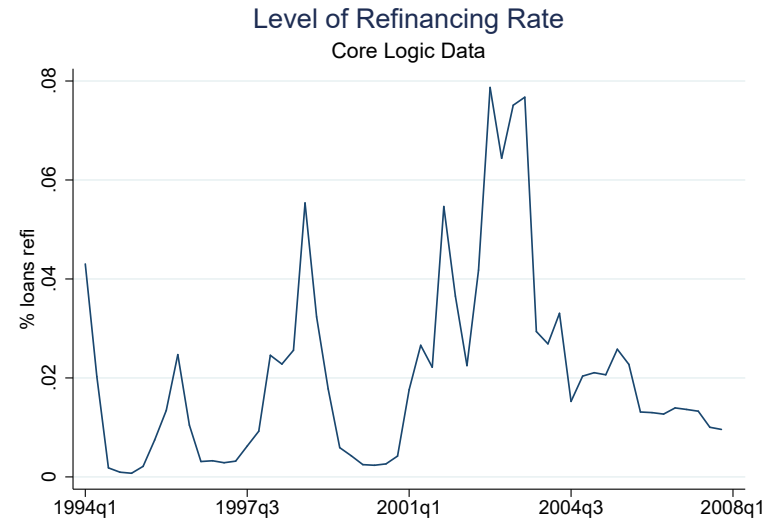

(c) Share of Refinancing With Cash-Out

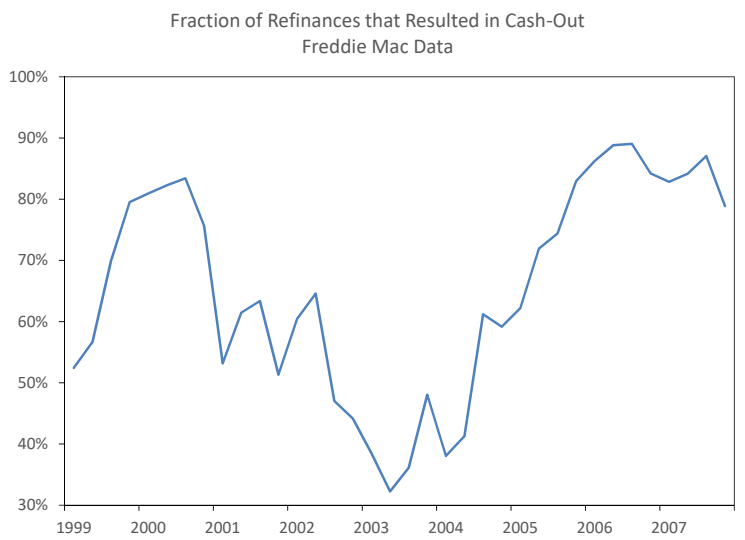

(b) Change in Refinancing Rate

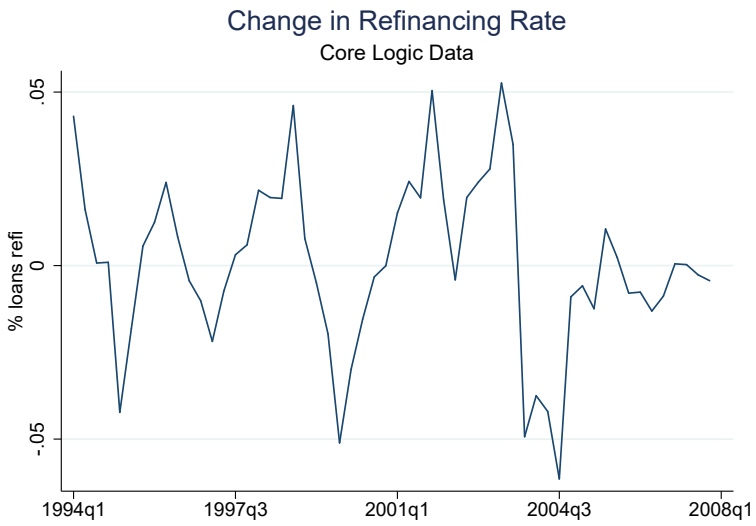

(d) Change in Share of Refi With Cash-Out

Differences in the Fraction of Refinances that Resulted in Cash-Out Freddie Mac Data

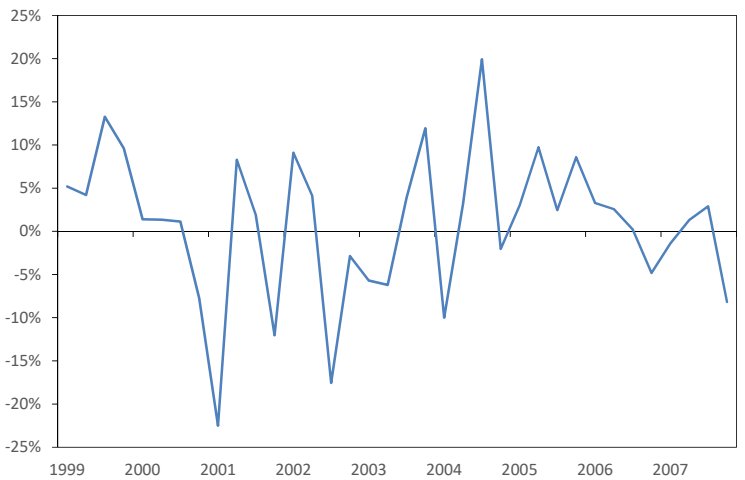

Notes: Panels (a) and (b) depicts the time series of the refinancing rate (fraction of loans that were refinanced in that quarter) and the quarterly change in the refinancing rate, respectively. Panels (c) and (d) depicts the time series of the share of refinanced loans that involved a balance increase (i.e. cash-out) and the quarterly change in this share, respectively. 
Figure 2: Distribution of interest rate gaps in 1997q4 and 2000q4

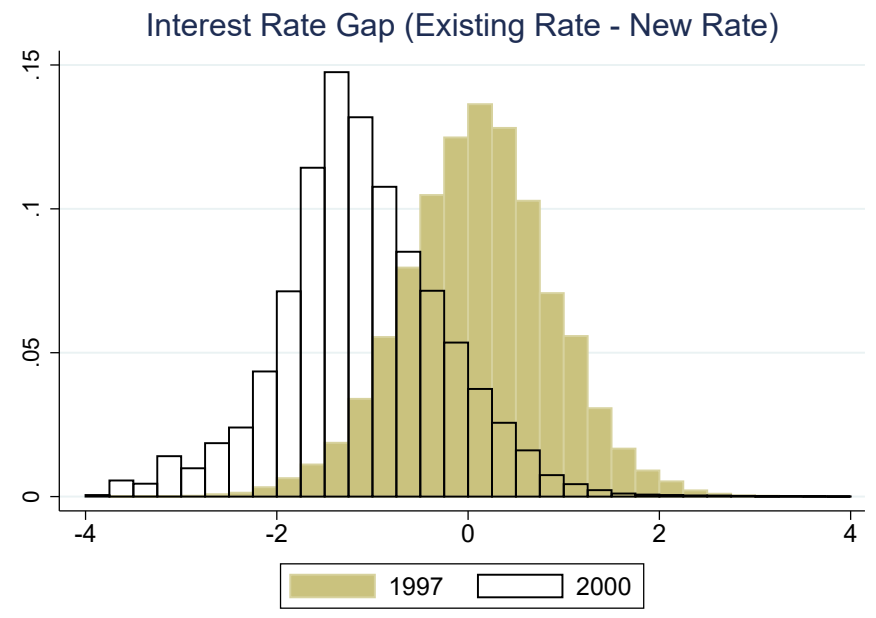

Notes: The figure depicts the distribution of interest-rate gaps across borrowers. The interest-rate gap is defined as the difference between the existing mortgage rate and the current market rate. See text for more details.

Figure 3: Cumulative Refinancing Rate in Response to a 50bp Mortgage Rate Cut

(a) Rate gap $=0$

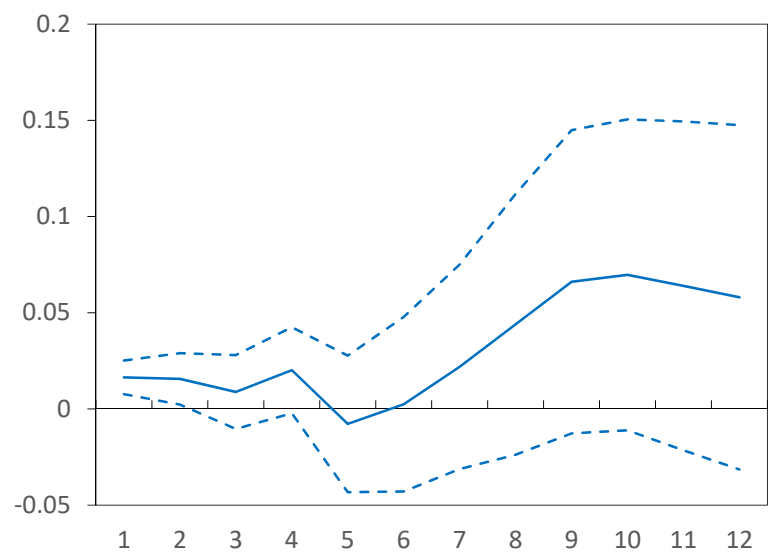

(b) Rate gap $=50 \mathrm{bps}$

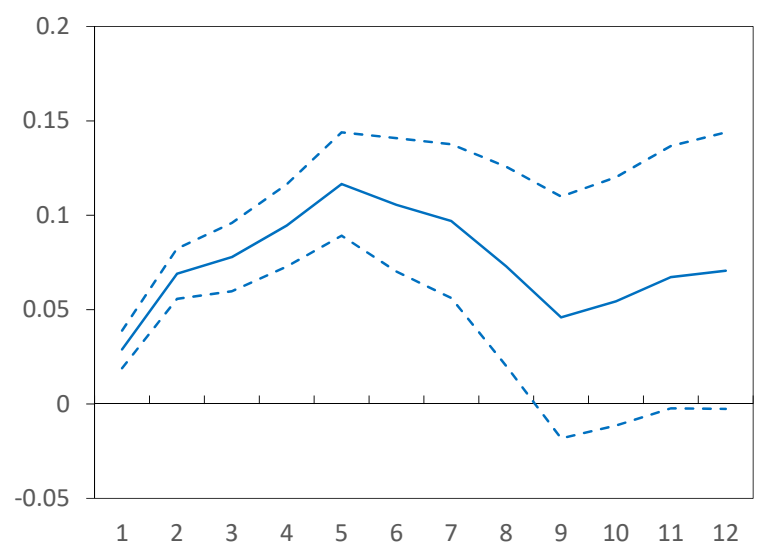

Notes: The figure depicts the cumulative response function of refinancing to a 50 bp decline in mortgage rates. Panel A shows the response if the initial average rate gap is zero. Panel B shows the response if the initial average rate gap is instead 50 basis points. 
Figure 4: Effect on the Refinancing Rate of a 50bp cut, at each point in time

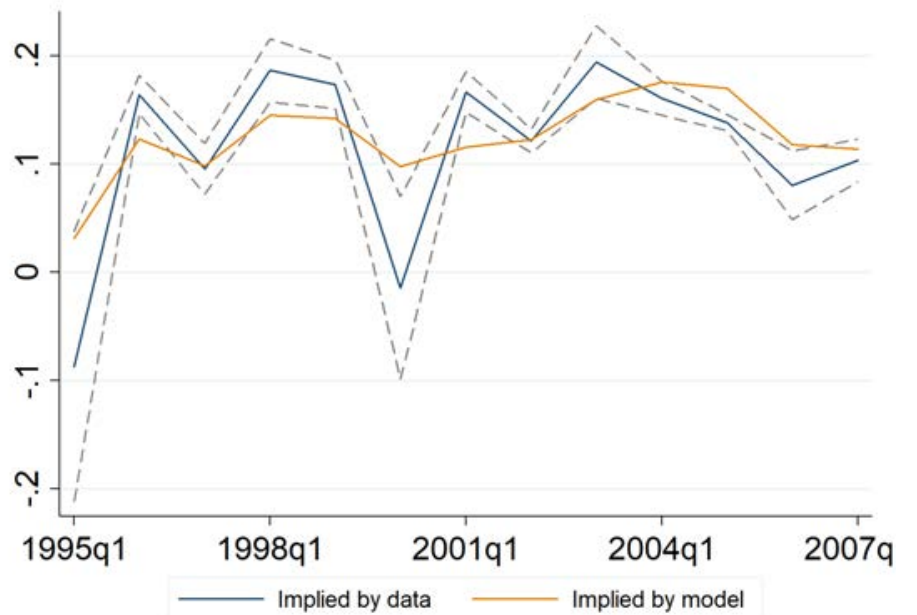

Figure 5: Time series of fitted and actual mortgage rates

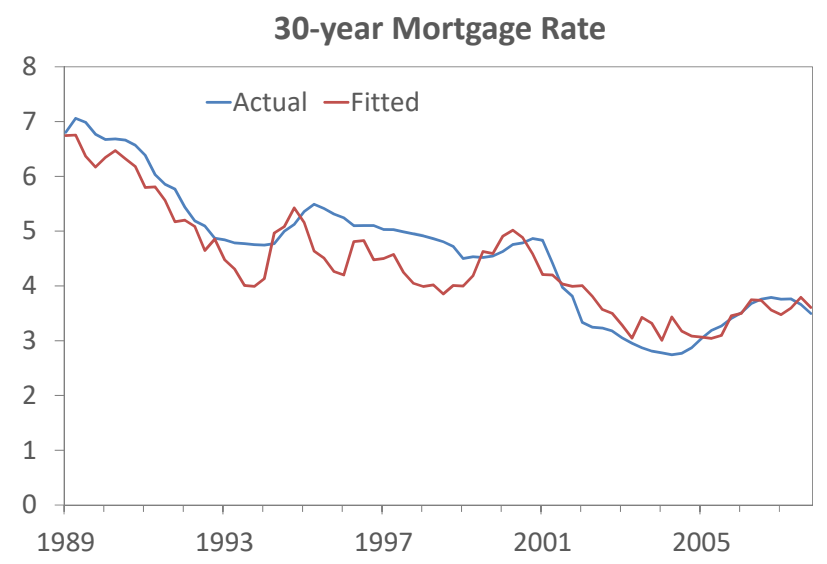

Notes: The figure depicts the fitted and actual mortgage rate data. See text for more details. 
Figure 6: Time series of fitted and actual house price to rent ratios

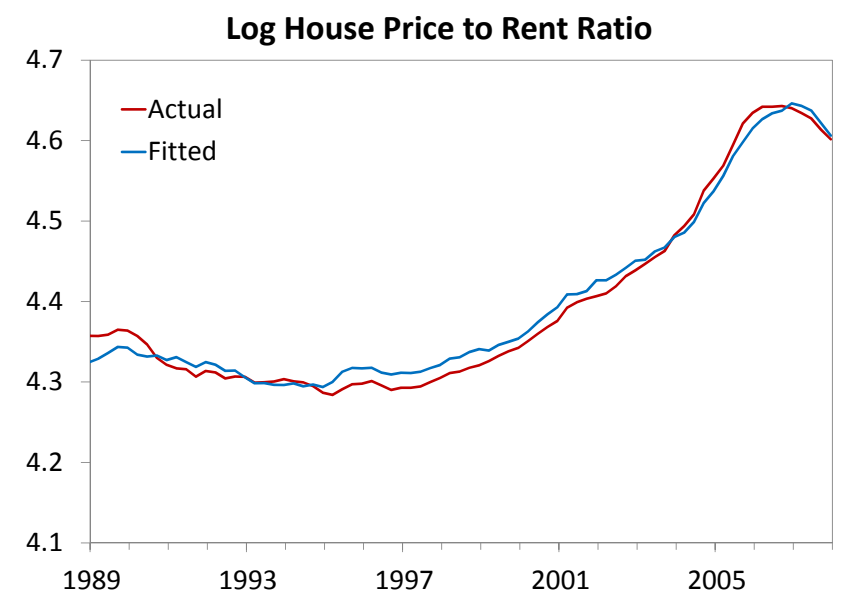

Notes: The figure depicts the fitted and actual house price to rental ratios. See text for more details.

Figure 7: Impulse response function of aggregate variables
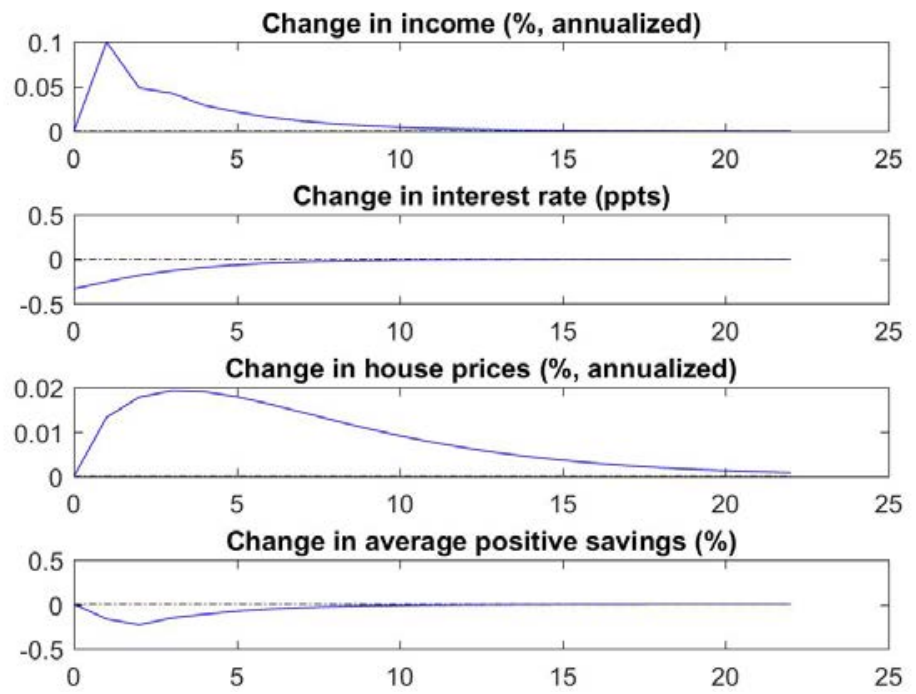

Notes: The figure depicts the impulse response function to a 1 sd interest rate shock. See text for details. 
Figure 8: Life-cycle moments
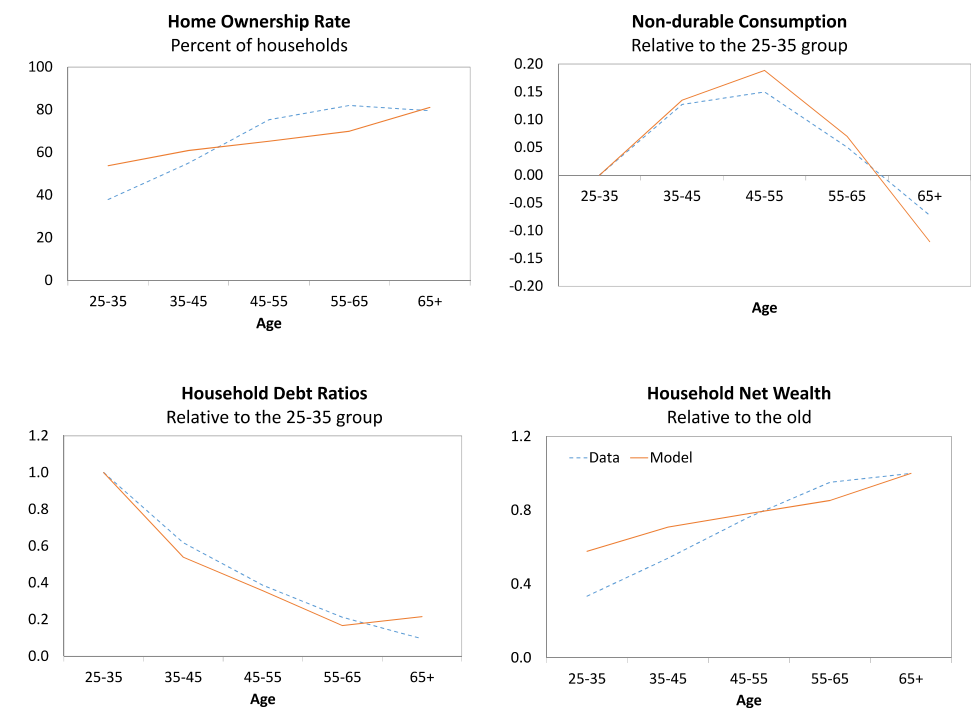

Notes: The figure depicts the fitted and actual life-cycle moments. See text for more details.

Figure 9: Refinancing, given the interest-rate gap

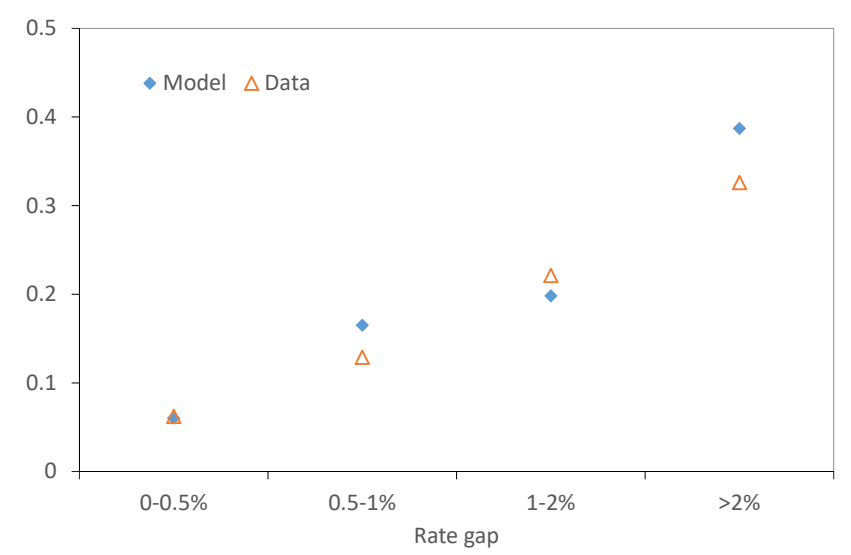

Notes: The figure depicts propensity to refinance for each given interest-rate gap in the data and the model. See text for more details. 
Figure 10: Alternative interest rate paths

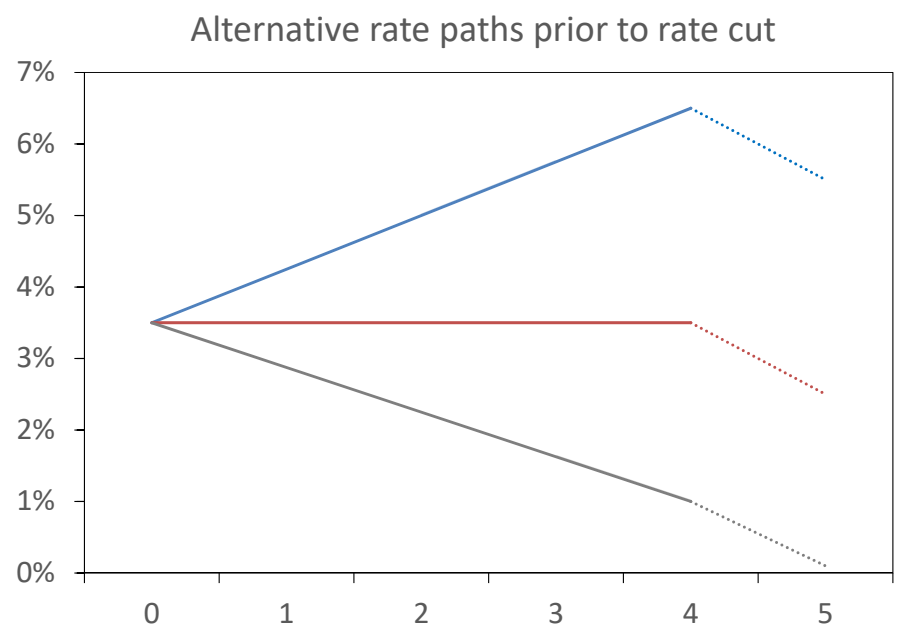

Notes: The figure depicts three alternative interest rate paths, starting at steady state. See text for more details.

Figure 11: Alternative interest rate paths

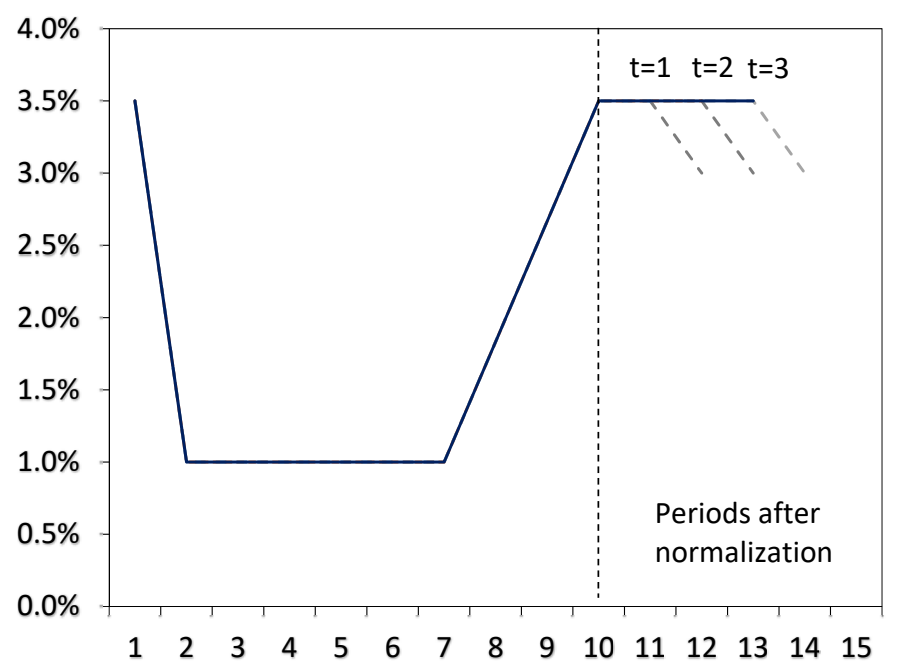

Notes: The figure depicts three alternative interest rate paths, starting at steady state. See text for more details. 


\section{Appendix}

\section{A County Data Description}

In this section, we describe our data sources and the construction of the county-level demographic variables used in our analysis.

For each county, we obtain the median age and the share of the population with a college degree from the Census, the unemployment rate and share of employment in manufacturing from the Bureau of Labor Statistics, and per-capita income from the Bureau of Economic Analysis.

We measure lender competitiveness using the Hirschman-Herfindahl Index computed across mortgage lenders within the county. ${ }^{1}$ This measure is also used in Scharfstein and Sunderam (2016). The index is constructed using data from HMDA (the Home Mortgage Disclosure Act).

We consider two measures of home values. Our first measure is the average home price accumulation over the life of the mortgage. We compute real house prices using the consumer price index. We then compute the log difference between the current home price and the value of the house at origination.

The median sale price of homes comes from two sources. We have monthly houseprice data from the Global Financial Data Real Estate database from 1975 to present. The home prices are based on information from Freddie Mac and Fannie Mae. For house prices prior to 1975, we use regional data from the U.S. Bureau of the Census and U.S. Department of Housing and Urban Development. The two different data series have very similar trends in the overlapping post-1975 period.

We use individual data on home equity to compute the average level of home equity. For each loan, we compute home equity (price minus the balance). We then winsorize the top and bottom 1 percent of the home equity values to abstract from outliers. Finally, we take an average across all loans within the county, weighted by loan balance.

\section{B Average Rate Gaps and County Characteristics}

In this section, we show how the average rate gap varies over time and across counties. We also show how the average rate gap correlates with observable county-level characteristics (unemployment rate, per capita income, share of college educated, home equity accumulation, median age, manufacturing share, and share of males in the population).

\footnotetext{
${ }^{1}$ We thank David Berger for sharing these data with us.
} 
Table 1: Average Rate Gap and County Characteristics

\begin{tabular}{|c|c|c|c|c|c|c|c|c|c|c|}
\hline Time FE & Yes & Yes & No & No & No & No & No & No & No & No \\
\hline County FE & Yes & No & Yes & No & No & No & No & No & No & No \\
\hline R-squared & 0.738 & 0.5432 & 0.1866 & 0.0546 & 0.0257 & 0.0119 & 0.0042 & 0.0004 & 0.0001 & 0.0001 \\
\hline Variables: & (I) & (II) & (III) & (IV) & (V) & $(\mathrm{VI})$ & (VII) & (VIII) & (XIV) & $(\mathrm{X})$ \\
\hline Unemployment rate & & & & $\begin{array}{c}0.0818^{* * *} \\
(0.010)\end{array}$ & & & & & & \\
\hline Per capita income & & & & & $\begin{array}{c}-0.3566 * * * \\
(0.020)\end{array}$ & & & & & \\
\hline Share colleged educated & & & & & & $\begin{array}{c}-0.5863^{* * *} \\
(0.050)\end{array}$ & & & & \\
\hline Home equity accumulation & & & & & & & $\begin{array}{c}-0.5117^{* * *} \\
(0.060)\end{array}$ & & & \\
\hline Median age & & & & & & & & $\begin{array}{c}0.0909^{*} \\
(0.040)\end{array}$ & & \\
\hline Manufacturing share & & & & & & & & & $\begin{array}{l}0.0003 \\
(0.000)\end{array}$ & \\
\hline Share male & & & & & & & & & & $\begin{array}{l}0.2296 \\
(0.410)\end{array}$ \\
\hline
\end{tabular}

The table below reports the estimated coefficient from regressing the average rate gap on the observable characteristic. Standard errors are given in parenthesis.

\section{Robustness}

\section{C.1 Alternative moments}

This section reports estimates of the state dependent effects of monetary policy using three alternative moments of the distribution of potential savings: the present value of potential savings, the fraction of loans with positive savings, and the spread of the existing mortgage rate relative to the threshold interest rate proposed by Agarwal, Laibson and Driscoll (2013). We find that the effects of a change in mortgage rates is state dependent, varying with the values of these alternative moments of the distribution.

First, we consider an alternative measure of the potential savings from refinancing based on the present value of savings from pursuing the following simple refinancing strategy: the existing loan is refinanced with a FICO-specific 30-year fixed-rate mortgage and the new loan is repaid over the remaining life of the mortgage being refinanced. To simplify the notation, we suppress the dependence of the interest rate on FICO score and region.

Consider a 30-year mortgage with a fixed interest rate $r^{\text {old }}$ that was originated at $T-30$ and matures at time $T$. The loan is repaid with fixed payments which we denote 
by Payment ${ }^{\text {old }}$. These payments are given by:

$$
\text { Balance }_{T-30}=\sum_{k=1}^{30} \frac{\text { Payment }^{\text {old }}}{\left(1+r^{\text {old }}\right)^{k}} .
$$

If the person refinances at the beginning of time $t$, before the mortgage payment is due, the balance owned on the old loan is given by the present value of the remaining payments:

$$
\text { Balance }_{t}=\sum_{k=t}^{T} \frac{\text { Payment }^{\text {old }}}{\left(1+r^{\text {old }}\right)^{(k-t)}} .
$$

The balance of the new mortgage is the same as that of the old mortgage. The new mortgage payment is computed assuming that the mortgage is paid off over a 30-year period:

$$
\text { Balance }_{t}=\sum_{k=1}^{30} \frac{\text { Payment }^{\text {new }}}{\left(1+r^{\text {new }}\right)^{k}} .
$$

The present value of savings associated with this refinancing strategy is:

$$
\text { Savings }_{t}=\left[\sum_{k=t}^{T} \frac{\text { Payment }^{\text {old }}-\text { Payment }^{\text {new }}}{\left(1+r^{\text {new }}\right)^{(k-t)}}\right]-\frac{\text { Balance }_{T}}{\left(1+r^{\text {new }}\right)^{T-t}},
$$

where Balance $_{T}$ is the balance of the refinanced mortgage at time $T$. We can rewrite equation (1) as:

$$
\text { Balance }_{t}+\text { Savings }_{t}=\left[\sum_{k=t}^{T} \frac{\text { Payment }^{\text {old }}}{\left(1+r^{\text {new }}\right)^{(k-t)}}\right] .
$$

This equation shows that if the household chooses its new mortgage so that the new mortgage payment is equal to the old mortgage payment, it can cash out Savings ${ }_{t}$. They do so by borrowing Balance $t+$ Savings $_{t}$, and using Balance $t$ to pay the old mortgage. With this strategy, the household takes out a mortgage loan that is larger than the existing mortgage loan and receives the difference between the two loans in cash.

We convert our nominal measures of potential savings into real terms using the Consumer Price Index (base year 1999). We construct this measure of savings for every mortgage at time $t$. We then compute the average level of savings at time $t$. We denote the average level of savings across mortgages by $A_{2 t}$ :

$$
A_{2 t}=\frac{1}{n_{t}} \sum_{i=1}^{n_{t}} \text { Savings }_{i t}
$$


The unconditional quarterly mean and standard deviation of the average savings from refinancing are -294 and 2,424 dollars, respectively.

We now discuss the estimates of regression (2) obtained for the case where $A_{t-1}^{c}$ is the average of savings from refinancing. Here, both $\beta_{1}$ and $\beta_{2}$ are significant at the one percent level. To interpret these coefficients, suppose that all the independent variables in regression (2) are initially equal to their time-series averages and that average of savings are initially equal to its mean value of $-\$ 294$. Our estimates in column 2 of Panel A of Table 2 imply that a 25 basis points drop in mortgage rates raises the share of loans refinanced by about 7.2 percent. Now suppose that the drop in mortgage rates happens when the average savings from refinancing is equal to $\$ 2,130$, which is the mean value of $(-\$ 294)$ plus one standard deviation $(\$ 2,424)$. Then, the refinancing rate rises to 10.4 percent. So, the marginal impact of a one standard-deviation increase in the average savings from refinancing is 2.5 percentage points.

Panels B and C of Table 2 consider two additional alternative moments of refinancing savings: the fraction of loans with positive savings, and the spread of the existing mortgage rate relative to the threshold interest rate proposed by Agarwal, Laibson and Driscoll (2013). We again find that the effects of a change in mortgage rates is state dependent, varying with the values of these alternative moments of the distribution.

\section{C.2 Instrumenting with the 2-year Treasury Yield}

This section provides additional estimates of the state dependent effects of monetary policy. In the main text, we instrumented for the response to a change in mortgage rate using high-frequency changes in the Federal Funds futures rate. Here, we show that the results are robust to instrumenting using the high-frequency changes in the 2-year Treasury yield within a 60-minute window around the Fed's announcement. Changes in the 2-year Treasury yield have been used as measures of monetary shocks by Gertler and Karadi (2015) and Gilchrist et al. (2015). Table 3 reports our estimates of regression specification (2), using the high-frequency changes in the 2-year Treasury yield as an instrument for changes in the mortgage rate. The estimated state dependent effects of monetary policy obtained using this alternative instrument are very similar to those reported in Tables 1 of the main text.

\section{C.3 Additional county-level controls}

In this section, we show that our estimates of the state dependent nature of the effects of monetary policy are robust to the inclusion of interactions between county-level controls and the change in mortgage rates. These estimates, reported in Table 4 below, are 
Table 2: State dependency of monetary policy and refinancing

\begin{tabular}{lcc}
\hline Refinancing over the year & $\begin{array}{c}\text { OLS } \\
\text { (I) }\end{array}$ & $\begin{array}{c}\text { IV } \\
\text { (II) }\end{array}$ \\
\hline Panel A & $0.045^{* * *}$ & $0.081^{* * *}$ \\
$\Delta \mathrm{R}(\mathrm{t})$ & $(0.005)$ & $(0.017)$ \\
& $0.021^{* *}$ & $0.028^{* *}$ \\
$\Delta \mathrm{R}(\mathrm{t}) \times$ Average savings & $(0.004)$ & $(0.009)$ \\
& & \\
Panel B & -0.022 & -0.004 \\
$\Delta \mathrm{R}(\mathrm{t})$ & $(0.033)$ & $(0.063)$ \\
& $0.140^{* *}$ & $0.183^{*}$ \\
$\Delta \mathrm{R}(\mathrm{t}) \times$ Fraction positive rate gap & $(0.058)$ & $(0.111)$ \\
& & \\
Panel C & $0.118^{* * *}$ & $0.253^{* * *}$ \\
$\Delta \mathrm{R}(\mathrm{t})$ & $(0.030)$ & $(0.088)$ \\
& $0.069^{* *}$ & $0.163^{*}$ \\
$\Delta \mathrm{R}(\mathrm{t}) \times$ Spread of old rate to ADL & $(0.028)$ & $(0.089)$ \\
threshold & & \\
\hline County Fixed Effects & Yes & Yes \\
SPF Controls & Yes & Yes \\
Additional county controls & Yes & Yes \\
\hline
\end{tabular}

Notes: Estimates from regression (2). IV is based on futures. Standard errors are in parentheses. 10, 5 , and 1 percent significance levels are denoted by ${ }^{*},{ }^{* *}$, and ${ }^{* * *}$, respectively. 
Table 3: State dependency of monetary policy and refinancing

\begin{tabular}{lc}
\hline & $(\mathrm{I})$ \\
\hline Panel A: Fraction refi & $0.094^{* * *}$ \\
$\Delta \mathrm{R}(\mathrm{t})$ & $(0.011)$ \\
& $0.224^{* *}$ \\
$\Delta \mathrm{R}(\mathrm{t}) \times$ Average rate gap & $(0.181)$ \\
& \\
Panel B: Fraction cash-out refi & $0.125^{* * *}$ \\
$\Delta \mathrm{R}(\mathrm{t})$ & $(0.015)$ \\
& $0.138^{* * *}$ \\
$\Delta \mathrm{R}(\mathrm{t}) \times$ Average rate gap & $(0.022)$ \\
& \\
Panel C: Change in balance, given cash-out refi & $0.280^{* * *}$ \\
$\Delta \mathrm{R}(\mathrm{t})$ & $(0.059)$ \\
& $0.253^{* * *}$ \\
$\Delta \mathrm{R}(\mathrm{t})$ x Average rate gap & $(0.067)$ \\
& \\
\hline County Fixed Effects & Yes \\
SPF Controls & Yes \\
Additional county controls & Yes \\
\hline
\end{tabular}

Notes: Estimates from regression (2). IV based on changes in the 2-year Treasury yield. Standard errors are in parentheses. ${ }^{*},{ }^{* *}$, and ${ }^{* * *}$ give significance at 10,5 , and 1 percent levels. 
Table 4: State dependency of monetary policy and refinancing

\begin{tabular}{|c|c|c|c|}
\hline & (I) & \multicolumn{2}{|c|}{ (II) } \\
\hline & \multicolumn{3}{|c|}{ coefficient std error coefficient std error } \\
\hline$\Delta R(t) \times$ Average rate gap $(t-1)$ & $0.266^{* * *} \quad(0.076)$ & $0.562^{* * *}$ & $(0.181)$ \\
\hline \multicolumn{4}{|l|}{$\Delta R(t) \times$ Average savings $(t-1)$} \\
\hline$\Delta R(t) \times$ Home equity $(t-1)$ & & 0.605 & $(0.584)$ \\
\hline$\Delta \mathrm{R}(\mathrm{t}) \times$ House price change $(\mathrm{t}-1)$ & & -0.229 & (0.171) \\
\hline$\Delta \mathrm{R}(\mathrm{t}) \mathrm{x}$ Unemployment rate $(\mathrm{t}-1)$ & & -0.030 & $(0.016)$ \\
\hline$\Delta R(t) \times$ Median age $(t-1)$ & & -0.001 & $(0.003)$ \\
\hline$\Delta R(t) \times$ Manufacturing share $(t-1)$ & & $0.008^{*}$ & $(0.003)$ \\
\hline$\Delta R(t) \times$ Share college $(t-1)$ & & 0.155 & $(0.154)$ \\
\hline$\Delta R(t) \times A R M$ share $(t-1)$ & & -0.004 & $(0.176)$ \\
\hline$\Delta \mathrm{R}(\mathrm{t}) \mathrm{x}$ Herfindahl index $(\mathrm{t}-1)$ & & 0.023 & $(0.026)$ \\
\hline County Fixed Effects & Yes & Yes & \\
\hline County interaction controls & No & Yes & \\
\hline
\end{tabular}

Notes: Estimates from regression (2). For comparison, we report the coefficients from Table 1 in the main text in this table's columns I and II. Column III is the estimated effects when we include the county demographics interacted with the change in mortgage rates. Standard errors are in parentheses. ${ }^{*},{ }^{* *}$, and ${ }^{* * *}$ give significance at 10,5 , and 1 percent levels.

similar to those in Table 1, in the main text. The fact that including interaction terms does not change the estimate elasticities implies that the state dependency that we highlight is distinct from other potential mechanisms explored in the literature. These mechanisms include, for instance, differential responses in refinancing to a decline in mortgage rates due to differences in competitiveness of the local lending market. It is also distinct from state dependency related to variation in the value of home equity across counties.

\section{OLS results}

The table below reports the OLS results corresponding to Table 2 of the main text. 
Table 5: State dependency of monetary policy and refinancing

\begin{tabular}{lc}
\hline & $(\mathrm{I})$ \\
\hline Panel A: Fraction refi & $0.041^{* * *}$ \\
$\Delta \mathrm{R}(\mathrm{t})$ & $(0.005)$ \\
& $0.096^{* *}$ \\
$\Delta \mathrm{R}(\mathrm{t}) \times$ Average rate gap & $(0.023)$ \\
& \\
Panel B: Fraction cash-out refi & $0.070^{* * *}$ \\
$\Delta \mathrm{R}(\mathrm{t})$ & $(0.003)$ \\
& $0.073^{* * *}$ \\
$\Delta \mathrm{R}(\mathrm{t}) \times$ Average rate gap & $(0.005)$ \\
& \\
Panel C: Change in balance, given cash-out refi & $0.137^{* * *}$ \\
$\Delta \mathrm{R}(\mathrm{t})$ & $(0.012)$ \\
& $0.045^{*}$ \\
$\Delta \mathrm{R}(\mathrm{t}) \times$ Average rate gap & $(0.025)$ \\
& \\
\hline County Fixed Effects & Yes \\
SPF Controls & Yes \\
Additional county controls & Yes \\
\hline
\end{tabular}

Notes: The table reports the response to a decline in interest rates. It therefore reports the estimates from regression equation (2), multiplied by -1 . Standard errors are in parentheses. ${ }^{*},{ }^{* *}$, and ${ }^{* * *}$ give the significance at the 10,5 , and 1 percent levels. 


\section{E Model aggregate process}

In our model, we assume that the aggregate state variables (log of aggregate income, $\log$ of house prices, and log of the real interest rate) evolve according to the vector autoregression process described in Equation (16), Section 6.2:

$$
\triangle S_{t}=B_{1} \triangle S_{t-1}+B_{2} \triangle \log \left(r_{t-1}\right) a_{t-1}+u_{t}
$$

where $B_{1}$ is a $4 \times 4$ matrix, $B_{2}$ is a $4 \times 1$ vector, and $u_{t}$ is a Gaussian disturbance.

We now provide evidence that the process does well relative to other specifications, in terms of the root-mean-squared error (RMSE). Table 6 below shows that none of the RMSE associated with the alternative specifications is smaller, taking sampling uncertainty into account, than the RMSE associated with specification (16). At the same time, specification (16) does have a statistically significant smaller RMSE than many alternative specifications.

The standard errors are computed as follows. We draw a set of coefficients from the joint distribution of estimated coefficients. We use the set of coefficients to construct one-step-ahead forecasts and compute the RMSE. We repeat these two steps for 100,000 draws of coefficients, and then compute the standard error of the RMSE.

Table 6: Root-mean-squared forecasting errors of regressions

\begin{tabular}{lcc} 
Regression & RMSE & SE \\
\hline$\triangle S_{t}=B_{1} \triangle S_{t-1}+B_{2} \triangle r_{t-1} a_{t-1}+u_{t}$ & 0.233 & 0.035 \\
$\triangle S_{t}=B_{1} \triangle S_{t-1}+u_{t}$ & 0.221 & 0.004 \\
$\triangle S_{t}=B_{1} \triangle S_{t-1}+B_{2} \triangle S_{t-2}+u_{t}$ & 0.293 & 0.008 \\
$\triangle S_{t}=B_{1} \triangle S_{t-1}+B_{2} \triangle S_{t-1} a_{t-1}+u_{t}$ & 0.309 & 0.099 \\
$S_{t}=S_{t-1}+B_{1} S_{t-1} A_{t-1}+u_{t}$ & 0.258 & 0.066
\end{tabular}




\section{F Model computation}

To solve the model numerically, we implement the following procedure. First, we reformulate the choice variables to rectangularize the problem and simplify computational issues that arise from the endogenous mortgage constraint. The problem is reformulated in terms of the leverage ratio, defined as

$$
q_{j a t}=b_{j a t} / p_{t} h_{j a t} \geq 0
$$

We solve the budget constraint for consumption and replace consumption in the utility function. The choices variables are therefore $s_{j a t}, h_{j a t}, 1$ (rent) $)_{j a t}, 1$ (adjust) jat,$q_{j a t}$. We discretize the idiosyncratic income variable $y_{j a t}$. We simulate the quarterly process for the aggregate state vector, $S_{t}$, to obtain the annual probability transition matrix for $S_{t}$. We discretize $S_{t}$ using the Rouwenhorst method. There are 32 grid points for $S_{t}$ and two grid points for $y_{j a t}$. The value functions ( $V^{\text {own } \& \text { noadjust }}\left(z_{j a t}\right), V^{\text {own \& adjust }}\left(z_{\text {jat }}\right)$ and $\left.V^{\text {rent }}\left(z_{j a t}\right)\right)$ are approximated as multilinear functions in the states, where $z_{j a t}=$ $\left[S_{t}, y_{j a t}, \operatorname{assets}_{j a t}\right]$. There are four endogenous states $\operatorname{assets}_{j a t}=\left[s_{j a t}, h_{j a t}^{o}, b_{j a t}, r_{j a t}\right]$. We use 10 knots for $b_{j a t}, s_{j a t}$, and $h_{j a t}^{o}$, and 5 knots for $r_{j a t}$. The knots are spaced more closely together near the constraints for $b_{j a t}$ and $s_{j a t}$. The value functions are interpolated between knots.

The model is solved via backward induction from the final period of life. At each age and each case, the optimal policies are computed using a Nelder-Meade algorithm, comparing the value functions for each of the three cases (to rent, to own a home and adjust the mortgage, to own a home and not adjust the mortgage) to generate the overall policy function.

To estimate the regression used in our empirical section with data simulated from the model, we proceed as follows. The model is initialized with the same distribution of wealth and mortgage rates for 1994, obtained from the Survey of Consumer Finances and the Core Logic database. We then feed the actual path for house prices, aggregate income, and interest rates for the period 1994-2007. Each cohort faces the historical path for the state variables, as well as the realized aggregate state variables. Given their individual and aggregate states, they make their consumption, mortgage, housing, and savings decisions. Given the observed decisions and states, we estimate the regression used in our empirical work and compare our model-based estimates with the empirical estimates. 